\title{
Retinal endothelial cell phenotypic modifications during experimental autoimmune uveitis: a transcriptomic approach
}

Deborah A. Lipski ${ }^{1,2^{*}+}$ D , Vincent Foucart ${ }^{1,3,4+}$, Rémi Dewispelaere ${ }^{1,3}$, Laure E. Caspers ${ }^{3}$, Matthieu Defrance ${ }^{5}$, Catherine Bruyns ${ }^{1}$ and François Willermain ${ }^{1,3,4}$

\begin{abstract}
Background: Blood-retinal barrier cells are known to exhibit a massive phenotypic change during experimental autoimmune uveitis (EAU) development. In an attempt to investigate the mechanisms of blood-retinal barrier (BRB) breakdown at a global level, we studied the gene regulation of total retinal cells and retinal endothelial cells during non-infectious uveitis.
\end{abstract}

Methods: Retinal endothelial cells were isolated by flow cytometry either in Tie2-GFP mice (CD31 ${ }^{+} \mathrm{CD}_{4} 5^{-} \mathrm{GFP}^{+}$ cells), or in wild type C57BL/6 mice (CD31 ${ }^{+} \mathrm{CD}^{-} 5^{-}$endoglin ${ }^{+}$cells). EAU was induced in C57BL/6 mice by adoptive transfer of IRBP1-20-specific T cells. Total retinal cells and retinal endothelial cells from naïve and EAU mice were sorted and their gene expression compared by RNA-Seq. Protein expression of selected genes was validated by immunofluorescence on retinal wholemounts and cryosections and by flow cytometry.

Results: Retinal endothelial cell sorting in wild type C57BL/6 mice was validated by comparative transcriptome analysis with retinal endothelial cells sorted from Tie2-GFP mice, which express GFP under the control of the endothelial-specific receptor tyrosine kinase promoter Tie2. RNA-Seq analysis of total retinal cells mainly brought to light upregulation of genes involved in antigen presentation and T cell activation during EAU. Specific transcriptome analysis of retinal endothelial cells allowed us to identify 82 genes modulated in retinal endothelial cells during EAU development. Protein expression of 5 of those genes (serpina3n, Icn2, ackr1, Irg1 and lamc3) was validated at the level of inner BRB cells.

Conclusion: Those data not only confirm the involvement of known pathogenic molecules but further provide a list of new candidate genes and pathways possibly implicated in inner BRB breakdown during non-infectious posterior uveitis.

Keywords: Uveitis, Inflammation, Blood-retinal barrier, RNA-Seq, Transcriptome, Endothelial cells, serpina3n, Lipocalin 2, ackr1, Irg1

\footnotetext{
* Correspondence: dlipski@ulb.ac.be

${ }^{\dagger}$ Deborah A. Lipski and Vincent Foucart contributed equally to this work.

'Ophthalmology Group, IRIBHM (Institut de Recherche Interdisciplinaire en

Biologie Humaine et Moléculaire), Université Libre de Bruxelles (ULB), Erasme

Campus, Building C, Room C6.117, 808 Route de Lennik, 1070 Brussels,

Belgium

${ }^{2}$ Ophthalmology Department of Erasme Hospital, Université Libre de

Bruxelles (ULB), 808 Route de Lennik, 1070 Brussels, Belgium

Full list of author information is available at the end of the article
}

(c) The Author(s). 2020, corrected publication 2023 Open Access This article is distributed under the terms of the Creative Commons Attribution 4.0 International License (http://creativecommons.org/licenses/by/4.0/), which permits unrestricted use, distribution, and reproduction in any medium, provided you give appropriate credit to the original author(s) and the source, provide a link to the Creative Commons license, and indicate if changes were made. The Creative Commons Public Domain Dedication waiver (http://creativecommons.org/publicdomain/zero/1.0/) applies to the data made available in this article, unless otherwise stated. 


\section{Background}

In physiological conditions, the eye is isolated from systemic circulation by an anatomical barrier that restricts the entry of potentially toxic molecules, pathogens and immune cells into the eye. The blood-retinal barrier (BRB) is composed of 2 distinct parts. On the one side, the outer BRB is formed by tight junctions between retinal pigment epithelial (RPE) cells, separating fenestrated choroidal vessels from the outer retina. On the other side, the inner BRB is formed by tightly sealed vascular non-fenestrated endothelial cells (ECs), surrounded by pericytes and supported by Müller cell and astrocyte foot processes. Similarly to the blood-brain barrier (BBB) in the central nervous system, many of the properties of the BRB are manifested in ECs [1].

Alteration of BRB properties is a hallmark of ocular inflammatory diseases. Although BRB breakdown may be beneficial, allowing immune cells to clear debris and repair damages, it can also be harmful, leading to edema by accumulation of water and plasma proteins, tissue damage by inflammatory cells and ultimately vision loss. During noninfectious posterior uveitis, activated $\mathrm{T}$ cells produce cytokines and chemokines that activate retinal vessels [2], resulting in a drastic change of retinal EC phenotype, comprising among others upregulation of adhesion molecules such as P selectin, ICAM-1 [3] and VCAM-1 [4] and downregulation of tight junction proteins [5]. This leads to the recruitment of a wide range of circulating leukocytes such as monocytes/macrophages, granulocytes, NK cells, NKT cells and $\gamma \delta$ T cells that are directly responsible for tissue damage [2]. The BRB then becomes increasingly permeable, allowing more immune cells into the eye, creating an amplification loop of the pathogenic process.

Although some individual alterations contributing to BRB dysfunction have been described, the underlying molecular mechanisms are still largely unknown. A transcriptomic study of total retinal cells and retinal ECs during experimental autoimmune uveitis (EAU) would thus represent an interesting approach to bring to light new target genes and signaling pathways involved in BRB breakdown. In the past decade, a few genome wide expression data sets have been generated for retinal ECs [6-18] (Table 1). Gene profiling studies have already confirmed that ECs from the immune-privileged central nervous system have a particular gene signature, compared to ECs in other tissues [1]. A few transcriptomic studies have been performed in human retinal ECs [12, 15, 17, 19]. Compared to uveal ECs, retinal ECs were found to express higher levels of transcripts involved in the immune response, including cell adhesion molecules, cytokines, chemokines, receptors and enzymes participating in the synthesis of inflammatory proteins. This is consistent with their suspected role in the regulation of leukocyte trafficking and inflammatory reaction during uveitis $[6,12]$. Furthermore, the expression of candidate genes such as adhesion molecules (e.g. ICAM-1, VCAM-1, E and P selectins) and chemokines (CXCL10, CCL20 and CX3CR1) was shown to be induced in cultured human ECs by inflammatory stimuli $[19,20]$. However, as illustrated in Table 1 , most studies were performed on cultured ECs, which rapidly lose their barrier properties [21]. Furthermore, although the effects of inflammatory stimuli by exposure to toxoplasma gondii, LPS or TNF- $\alpha[7,15,17,18]$ on gene expression were explored in EC cultures, to the best of our knowledge no study has investigated yet how EC gene expression is affected in vivo during non-infectious uveitis.

In this work, we have decided to analyze the transcriptome of freshly isolated total retinal cells and retinal ECs from EAU and naïve retinas used as control. Using RNA-Seq, we identified a series of genes that are modulated during EAU development. The expression of some of those genes was then analyzed by immunofluorescence (IF) and flow cytometry.

\section{Methods \\ Reagents and animals}

Interphotoreceptor retinoid-binding peptide (IRBP) 1-20 (Ac-GPTHLFQPSLVLDMAKVLD-amide), representing residues 1-20 of human IRBP, was synthesized by New England Peptide (Gardner, MA., USA). Pertussis toxin (PTX) and complete Freund's adjuvant (CFA) were purchased from Sigma-Aldrich (Bornem, Belgium). Pathogen-free female C57BL/6 J mice (6- to 10-weeks old), purchased from Janvier (Genest St Isle, France) were housed at the animal facilities in accordance with European guidelines. FVB/N homozygous Tie2-GFP transgenic male mice (Tg(TIE2GFP)287Sato/J, stock number 003658), which express green fluorescent protein (GFP) under the control of the endothelial-specific receptor tyrosine kinase Tie2 (or Tek) promoter, were purchased from Jackson Laboratories (Bar Harbor, ME). Animal treatment conformed to the ARVO Statement for the Use of Animals in Ophthalmic and Vision Research. All cells were cultured in RPMI 1640 medium supplemented with $25 \mathrm{mM}$ HEPES, 10\% fetal bovine serum, 1\% L-glutamine, 1\% sodium-pyruvate, $100 \mathrm{IU} / \mathrm{ml}$ penicillin, $100 \mathrm{~g} / \mathrm{ml}$ streptomycin, $5.10^{-5} \mathrm{M} \beta$ mercaptoethanol in a $5 \% \mathrm{CO} 2$ and $95 \%$ humidity incubator.

\section{Backcrossing and genotyping}

Two FVB/N Tie2-GFP males (Tg(TIE2GFP)287Sato/J, stock number 003658) were paired with wild type (WT) C57BL/6 J female mice. C57BL/6 J-Tie2-GFP mice were then generated by backcrossing genetically selected Tie2-GFP carrier males with WT C57BL/6 J females over 10 generations. The resulting litters from each pairing were genotyped by standard PCR amplification of the transgene on genomic DNA extracted from tail tissue samples, as suggested by Jackson Laboratories. 
Table 1 Recent genome wide expression data sets for retinal endothelial cells

\begin{tabular}{|c|c|c|c|c|c|}
\hline Study & Method of retinal EC isolation & $\begin{array}{l}\text { Method of } \\
\text { gene } \\
\text { expression } \\
\text { analysis }\end{array}$ & Species & Other cells studied & Disease/ conditions \\
\hline $\begin{array}{l}\text { Zhao et } \\
\text { al., } 2016 \\
{[6]}\end{array}$ & Cultured human retinal ECs (HRECs) & $\begin{array}{l}\text { miRNA } \\
\text { microarray }\end{array}$ & Human & / & $\begin{array}{l}\text { Exposure to normal glucose or high } \\
\text { glucose }\end{array}$ \\
\hline $\begin{array}{l}\text { Savage et } \\
\text { al., } 2015 \\
\text { [7] }\end{array}$ & $\begin{array}{l}\text { Cultured human retinal } \\
\text { microvascular ECs (HRMEC) }\end{array}$ & RNA-Seq & Human & / & $\begin{array}{l}\text { Exposure to TNF-a in the presence or } \\
\text { absence of the NFAT-specific inhibitor } \\
\text { INCA-6 vs vehicle-treated control }\end{array}$ \\
\hline $\begin{array}{l}\text { Wang et } \\
\text { al., } 2013 \\
{[8]}\end{array}$ & $\begin{array}{l}\text { Freshly isolated mouse microvessels } \\
\text { (CD31-based magnetic purification) }\end{array}$ & Microarray & Mouse & / & $\begin{array}{l}\text { Cells from } r d 1, \text { VIdlr } r^{-/-} \text {and } \mathrm{Grh} / 3^{c t} / J \text { curly } \\
\text { tail mice (mutants with remodelling of the } \\
\text { retinal vasculature) vs naive C } 75 \mathrm{BL} / 6 \mathrm{~J}\end{array}$ \\
\hline $\begin{array}{l}\text { Kusuhara } \\
\text { et al., } \\
2012[9]\end{array}$ & $\begin{array}{l}\text { FACS based on GFP expression in P8 } \\
\text { Tie2GFP transgenic mice }\end{array}$ & Microarray & Mouse & GFP- retinal cells & / \\
\hline $\begin{array}{l}\text { Steinle et } \\
\text { al., } 2012 \\
{[10]}\end{array}$ & Cultured human retinal ECs & Microarray & Human & / & $\begin{array}{l}\text { Melphalan or carboplatin treatment vs } \\
\text { untreated cells }\end{array}$ \\
\hline $\begin{array}{l}\text { Takase et } \\
\text { al., } 2012 \\
{[11]}\end{array}$ & $\begin{array}{l}\text { FACS based on GFP expression in } \\
\mathrm{Flk} 1^{+} / \mathrm{GFP} \text { embryos }\end{array}$ & Microarray & Mouse & $\begin{array}{l}\text { Whole WT and Flk1 KO } \\
\text { embryos }\end{array}$ & / \\
\hline $\begin{array}{l}\text { Browning } \\
\text { et al., } \\
2011[12]\end{array}$ & $\begin{array}{l}\text { Retinal EC cultures from } 3 \text { human } \\
\text { donors (CD31-based magnetic } \\
\text { purification) }\end{array}$ & Microarray & Human & $\begin{array}{l}\text { Donor-matched iris and } \\
\text { choroidal ECs + cultured } \\
\text { human umbilical vein ECs } \\
\text { (HUVEC) }\end{array}$ & / \\
\hline $\begin{array}{l}\text { Strasser et } \\
\text { al., } 2010 \\
{[13]}\end{array}$ & $\begin{array}{l}\text { Laser capture microdissection of } \\
\text { retinal endothelial tip cells and } \\
\text { endothelial stalk cells 24-36h after } \\
\text { birth }\end{array}$ & Microarray & Mouse & / & / \\
\hline $\begin{array}{l}\text { Abukawa } \\
\text { et al., } \\
2009 \text { [14] }\end{array}$ & $\begin{array}{l}\text { Conditionally immortalized rat retinal } \\
\text { capillary ECs (TR-iBRB2) }\end{array}$ & Microarray & Rat & / & $\begin{array}{l}\text { Incubation with Müller cell conditioned } \\
\text { medium vs control }\end{array}$ \\
\hline $\begin{array}{l}\text { Smith et } \\
\text { al., } 2007 \\
{[15]}\end{array}$ & $\begin{array}{l}\text { Separate primary retinal EC cultures } \\
\text { from } 6 \text { human donors (CD31-based } \\
\text { magnetic purification) }\end{array}$ & Microarray & Human & $\begin{array}{l}\text { Donor-matched choroidal } \\
\text { ECs }\end{array}$ & $\begin{array}{l}\text { Exposure to Toxoplasma gondii } \\
\text { tachyzoïtes or LPS vs control }\end{array}$ \\
\hline $\begin{array}{l}\text { Ohtsuki et } \\
\text { al., 2005 } \\
{[16]}\end{array}$ & $\begin{array}{l}\text { Conditionally immortalized rat retinal } \\
\text { capillary ECs (TR-iBRB2 and TR-iBRB9) }\end{array}$ & $\begin{array}{l}\text { mRNA } \\
\text { differential } \\
\text { display } \\
\text { analysis }\end{array}$ & Rat & Brain capillary ECs (TR-BBB) & / \\
\hline $\begin{array}{l}\text { Silverman } \\
\text { et al., } \\
2005 \text { [17] }\end{array}$ & $\begin{array}{l}\text { Separate retinal EC cultures from } 4 \\
\text { human donors (CD31-based } \\
\text { magnetic purification) }\end{array}$ & Microarray & Human & Donor-matched iris ECs & Exposure to LPS or TNF-a vs control \\
\hline $\begin{array}{l}\text { Knight et } \\
\text { al., } 2005 \\
{[18]}\end{array}$ & $\begin{array}{l}\text { Immortalized rat retinal vascular ECs } \\
\text { (SV40 large T immortalized cell line } \\
\text { JG2/1) }\end{array}$ & Microarray & Rat & / & Exposure to Toxoplasma gondii vs control \\
\hline
\end{tabular}

Pubmed search conducted with the terms transcriptome/ RNA-Seq/ microarray/ genome wide AND endothelial/ endothelium/ vascular AND retina

\section{Adoptive transfer model of experimental autoimmune uveitis}

EAU was induced by adoptive transfer (AT) of autoreactive lymphocytes following the protocol of Shao $\mathrm{H}$ et al. [22]. Briefly, naive C57BL/6 J mice were immunized with a subcutaneous injection in each hind leg of $50 \mu \mathrm{l}$ of a mixture containing $500 \mu \mathrm{g} / 100 \mu \mathrm{l}$ IRBP peptide $1-20$ in a 1:1 emulsion of CFA enriched with $2.5 \mathrm{mg} / \mathrm{ml}$ of heat-inactivated Mycobacterium tuberculosis. All animals received simultaneously an intraperitoneal injection of $1 \mu \mathrm{g}$ of PTX. Twelve days after immunization, mice were euthanized by cervical dislocation and their spleen and draining lymph nodes dissected and dissociated. Spleen cell suspensions were enriched in $\mathrm{T}$ lymphocytes through passage on nylon wool fiber columns, then pooled with total lymph node cells and re-stimulated in vitro with IRBP1-20 $(1 \mu \mathrm{g} / \mathrm{ml})$. After 2 days in culture, cells were injected intraperitoneally into naive $\mathrm{C} 57 \mathrm{BL} / 6 \mathrm{~J}$ mice $\left(5 \times 10^{6}\right.$ cells/mouse $)$.

\section{Disease grading}

A clinical grading was performed 21 days after AT. Mice were anaesthetized by a $50 \mu \mathrm{l}$ intraperitoneal injection of a 
Rompun $(0,2 \%)$ and Ketalar $(20 \mathrm{mg} / \mathrm{ml})$ mixture. Pupils were dilated with tropicamid $(5 \mathrm{mg} / \mathrm{ml})$ and phenylephrine $(1.5 \mathrm{mg} / \mathrm{ml})$ and eyes were examined under the slit-lamp of a surgical microscope (Zeiss, Göttingen, Germany) by using a cover slip coated in a viscoelastic gel (synthetic polymer of acrylic acid $2 \mathrm{mg} / \mathrm{g}$, Vidisic, Tramedico, Belgium) and positioned on the cornea. The clinical grading was performed independently by two ophthalmologists, based on a system adapted from $\mathrm{Xu}$ et al. [23]. Briefly, vitritis, optic neuropathy, retinitis and vasculitis were separately scored in each eye, from 0 (no disease) to 4 (highly severe disease) with half point increments and averaged to generate the clinical score of the eye on a scale from 1 to 4 . The clinical score attributed to one mouse corresponds to the mean of the scores of the 2 eyes. The animals were euthanized by cervical dislocation.

\section{Immunohistology}

\section{Immunofluorescence stainings on retinal cryosections}

At day 21 after disease induction, mice were euthanized by cervical dislocation while still anaesthetized and unconscious (see section 4.4). Eyes were collected, prefixed for $6 \mathrm{~h}$ at $4{ }^{\circ} \mathrm{C}$ in PFA (paraformaldehyde) $4 \%$, sucrose $3 \%$ and then put in three successive baths containing 5 , 10 and $18 \%$ sucrose in phosphate-buffered saline (PBS), respectively, for $24 \mathrm{~h}$ each. Entire eyes were embedded in OCT medium (Sakura, Antwerp, Belgium) and cut in $16 \mu \mathrm{m}$-thick frozen sections using a cryostat (CM3050S Leica). The MOM (mouse-on-mouse) Basic Kit (Vector Laboratories, Labconsult, Brussels) was used to prevent high background staining. Cryosections were fixed with PFA $4 \%$ for $15 \mathrm{~min}$ and blocked in TBS (Tris $10 \mathrm{mM}$, $\mathrm{NaCl}$ 0.9\%, pH 7.6) supplemented with MOM IgG blocking solution and Triton $0.3 \%$ for $2 \mathrm{~h}$. Sections were incubated overnight with the following primary antibodies, alone or in different combinations as indicated in results: anti-endoglin (goat, 1/200; BD Biosciences), anti-CD31 (rat, 1/200, BD Biosciences), anti-lrg1 (rabbit, 1/100, Proteintech, Manchester), anti-serpina3n (goat, 1/200, $R \& D$ systems), anti-lcn2 (goat, R\&D systems), antilamC3 (1/10000, generous gift from W. J. Brunken) and anti-ackr1 (1/2000, generous gift from U. von Andrian) and diluted in TBS supplemented with MOM kit protein concentrate. After three washings in TBS, the sections were incubated in the dark for $1 \mathrm{~h} 30$ with speciesspecific secondary antibodies coupled to different fluorochromes, as indicated in data, then with Hoechst to stain the nuclei (Invitrogen, Gent, Belgium). After several washings, sections were mounted in Glycergel (Dako, Agilent Technologies, Diegem, Belgium) supplemented with 2.5\% Dabco (Sigma-Aldrich). Pictures of immunostainings were acquired using an AxioImager Z1 microscope equipped with an AxioCamMR camera (Carl Zeiss, Inc.) and the z-stack mode of the Axiovision acquisition software. Z-stacks were processed using the Imaris deconvolution software.

\section{Immunofluorescence stainings on retinal wholemount preparations}

At day 21 after disease induction, mice were euthanized by cervical dislocation while still anaesthetized and unconscious (see section 4.4). Eyes were collected and immediately immersed in PFA $4 \%$ for $1 \mathrm{~h}$ at $4{ }^{\circ} \mathrm{C}$. Eyes were then dissected in ice-cold PBS: the anterior segment of the globe, crystalline lens and vitreous were removed and the retina was carefully peeled from the RPE. Whole retinas were fixed in $70 \%$ ethanol for $1 \mathrm{~h}$, rinsed 3 times in PBS (10 min each), blocked with a solution containing $3 \%$ milk and $3 \%$ bovine serum albumin (BSA) in PBS for $1 \mathrm{~h}$ and incubated with different combinations of primary antibodies in a PBS-BSA1\% solution overnight at room temperature. Retinas were rinsed 3 times in PBS (20 min each) and incubated sequentially for $1 \mathrm{~h}$ with each secondary antibody. After 3 final washings in PBS ( $20 \mathrm{~min}$ each), the retinas were flattened by radial incisions and mounted with Vectashield antifade mounting medium with DAPI (Labconsult, Brussels).

\section{Preparation of retinal single cell suspensions}

At day 21 after disease induction, mice were euthanized by cervical dislocation while still anaesthetized and unconscious (see section 4.4), and the eyes immediately enucleated. Naïve eyes were used as control. Eyes were carefully hemisected in Hank's Balanced Salt Solution (HBSS) buffer containing penicillin/streptomycin 1\%, with surgical scissors under a surgical microscope. Retinal tissue was isolated and rinsed in HBSS buffer. The 2 retinas of each mouse were pooled and cut into small pieces before enzymatic digestion in $3 \mathrm{ml}$ HBSS containing $1,6 \mathrm{mg} / \mathrm{ml}$ Liberase DL (Roche, Vilvoorde, Belgium) and $0,1 \mathrm{mg} / \mathrm{ml}$ DNase I (Sigma-Aldrich) at $37^{\circ} \mathrm{C}$ for 45 min. Cell dissociation was stimulated by pipetting every 15 min. Cells were washed with Dulbecco modified eagle medium (DMEM) $/ 10 \%$ fetal bovine serum (FBS) and filtered through a $40-\mu \mathrm{m}$ cell strainer to obtain a single cell suspension [24]. The yield was approximately 2 to 3 million retinal cells per mouse.

\section{Fluorescence-activated cell sorting (FACS) analysis}

Retinal single cell suspensions were tested by flow cytometry for the expression of GFP, endoglin (CD105, endothelial cell marker), CD31 (PECAM-1, endothelial cell marker), CD45 (pan-leukocyte marker), ackr1, $\operatorname{lrg} 1$ and lamc3 using specific antibodies (BD Biosciences) coupled to different fluorochromes, except for GFP whose native fluorescence was observed. Cells were incubated with the relevant antibodies for $20 \mathrm{~min}$ at $4{ }^{\circ} \mathrm{C}$, washed and re-suspended in FACS buffer. Live cells 
were gated with Hoechst 1/4000 and debris and doublets were excluded. Up to one million total cells per sample were analyzed on an LSR-Fortessa flow cytometer using the CellQuest Software (BD Biosciences). Isotypes and Fluorescence minus one (FMO) controls were used for accurate gating. Compensations were performed using BD CompBeads (BD Biosciences).

\section{Analysis of retinal cell gene expression}

Purification of total retinal cells and retinal endothelial cells

Three weeks after AT, mice were sacrificed, and retinal single cell suspensions prepared as described above. Naïve eyes were used as controls. Cells were stained with APC-labeled anti-CD31, PECy7-labeled anti-CD45 and when applicable PE-labeled anti-endoglin antibodies. Total live retinal cells (DAPI-) and then retinal ECs (either GFP + CD31 + CD45or endoglin+CD31 + CD45- cells) were separately sorted by preparative flow cytometry using a FACSAria with the FACSDiva Software (BD). Due to the low cell number obtained from each mouse, at least 3 mice were pooled to generate each EAU sample and at least 2 mice for naïve samples. Cells were sorted directly in lysis buffer, vortexed for $30 \mathrm{~s}$ and flash frozen in liquid nitrogen.

\section{RNA extraction}

RNA extraction was performed using the MiRNeasy MicroKit (Qiagen) according to the manufacturer's recommendations and a DNase step to avoid DNA contamination. RNA quality was assessed using the Agilent 2100 Bioanalyzer with RNA 6000 Pico kit (Agilent Technologies).

\section{RNA processing and RNA sequencing}

Indexed cDNA libraries were prepared using the Ovation Single Cell RNA-Seq system (Nugen) (for samples isolated from transgenic mice) or the Ovation SoLo RNAseq system (Nugen) (for samples isolated from WT mice, since the Ovation Single Cell RNA-Seq system was then no longer available from Nugen). The multiplexed libraries were loaded, and sequences were produced using a TruSeq PE cluster and SBS-kit on a HiSeq 1500 (Illumina). Approximately 25 million paired-end reads/ sample were mapped against the mouse reference genome (NCBI Build 37/UCSC mm9) using STAR software to generate read alignments for each sample. Expression levels were quantified using the featureCounts [25] tool and the UCSC RefSeq gene annotation as a reference (exons only, genes as meta features). Differential analysis between groups was performed using the EdgeR package (quasi-likelihood F-tests). Normalized expression levels were estimated using the EdgeR rpm function and converted to $\log _{2}$ FPKM (fragments per kilobase of exon per million mapped reads) after resetting low FPKMs to 1.
To perform blind clustering analysis, genes were selected based on the overall variance between samples (independently of their category), by keeping only the 120 most variant ones. Functional analysis was performed using the Database for Annotation, Visualization, and Integrated Discovery (DAVID) web-based functional annotation tool [26].

\section{Results}

In an attempt to investigate the local mechanisms of non-infectious posterior uveitis development at a global level, we aimed to study the gene regulation of total retinal cells and more specifically retinal ECs during EAU.

We first set up a method to purify and gene profile BRB-forming retinal ECs. We then compared the transcriptional profile of total retinal cells during AT EAU to that of naïve mice and finally performed the same analysis for retinal ECs.

\section{Purification and gene profiling of naïve retinal endothelial cells}

The first challenge to be addressed pertained to the isolation of retinal ECs, which represent a small percentage of cells to extract from an already very small tissue.

As a first approach to retinal EC sorting, we decided to use transgenic Tie2-GFP mice, which express GFP under the control of the pan-endothelial Tie2 promoter (transgenic strategy). However, FVB/N-Tie2-GFP mice are not susceptible to EAU induction, as shown in Additional file 1: Fig. S1. We thus generated C57BL/6 J-Tie2-GFP mice by crossing founder FVB/N-Tie2-GFP males with WT C57BL/6 J mice and subsequently backcrossing genetically selected Tie2-GFP carrier males with WT C57BL/6 J females over 10 generations. In order to validate the specificity of GFP expression in retinal ECs, we first analyzed comparatively the expression of GFP with that of CD31 and endoglin (2 EC markers) in the retina of naive heterozygous Tie2-GFP mice by immunofluorescence (IF) on eye cryosections. Figure 1 shows that the expression of GFP matches that of CD31 and endoglin in the retina of naive heterozygous Tie2-GFP mice. Unfortunately, we unexpectedly observed an extremely low transmission rate of the Tie2-GFP allele with successive backcrossing generations (Additional file 2: Fig. S2). Indeed, while $100 \%$ of F1 mice were carriers, the proportion dropped to $0 \%$ for F10 mice.

We thus developed an alternative EC sorting strategy in C57BL/6 J WT mice, based on combined expression of the 2 retinal EC markers, CD31 and endoglin, that were previously tested by IF in Fig. 1 (WT strategy). We first analyzed CD31 and endoglin expression on AT EAU eye cryosections from WT C57BL/6 J mice by IF (Fig. 2). During EAU, retinal vessels are well identified by CD31 and endoglin stainings (Fig. 2, thin arrows). 

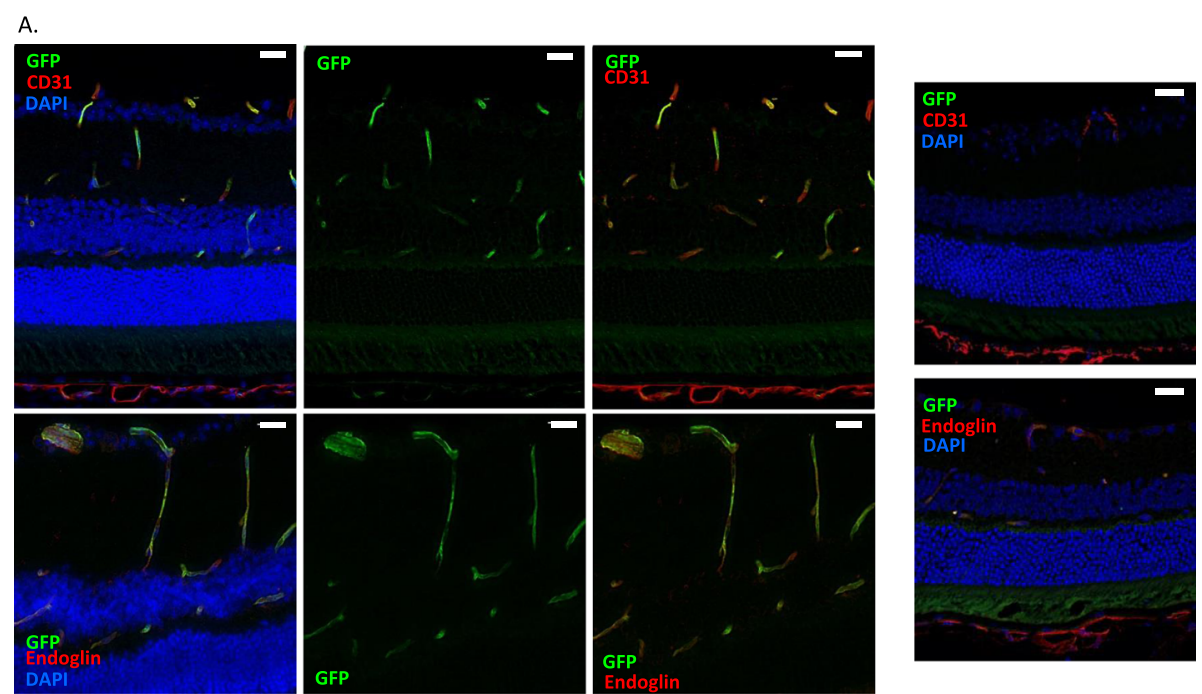

Fig. 1 GFP is expressed by endothelial cells in heterozygous Tie2-GFP FVB/N-C57BL/6 J mice. Immunofluorescence analysis: eye cryosections of heterozygous Tie2-GFP FVB/N-C57BL/6 naïve mice (left) were prepared and stained for GFP (green) and either CD31 (top) or endoglin (bottom) (red) detection. WT C57BL/6 naive eyes were used as control (right). Cell nuclei were stained with Hoechst (blue). Each picture was chosen as representative of an experiment conducted on 3 or more animals. Scale bars indicate $20 \mu \mathrm{m}$
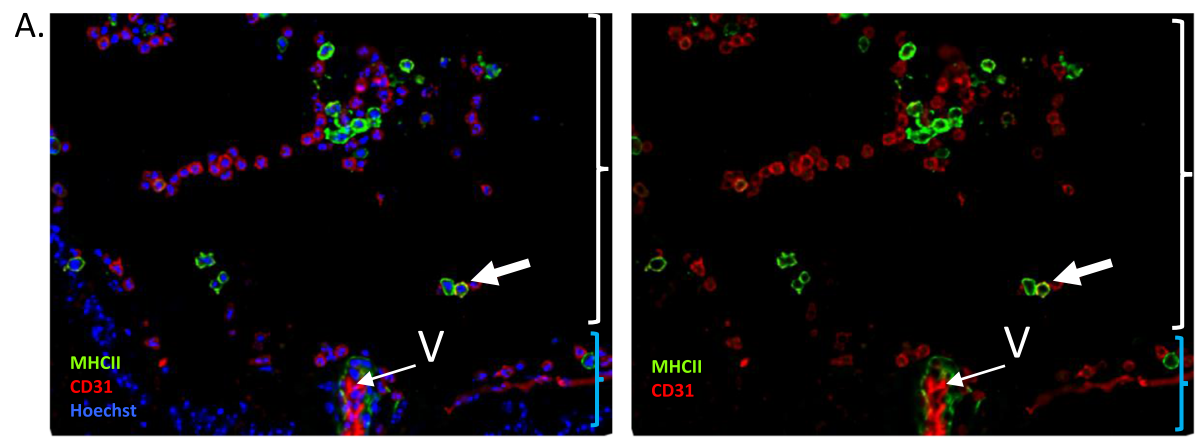

B.
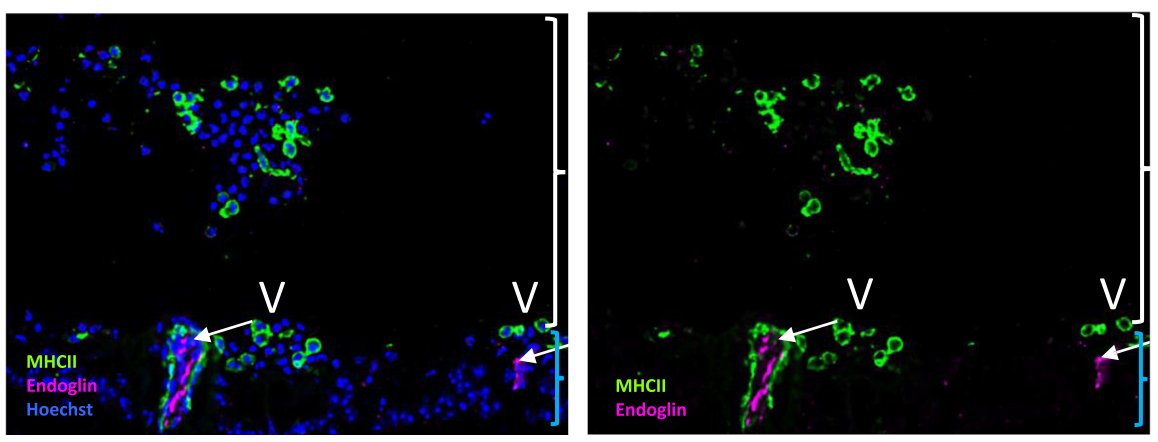

Fig. 2 Expression of endothelial cell markers CD31 and endoglin in the retina during experimental autoimmune uveitis. Three weeks after adoptive transfer, eye cryosections were prepared and stained for MHC Class II (used as disease marker, green) and CD31 (red) or endoglin (magenta) detection. Cell nuclei were stained with Hoechst (blue). Each picture was chosen as representative of an experiment conducted on 3 or more animals. a. CD31 expression in the retina during EAU. b. Endoglin expression in the retina during EAU. Thin arrows point to endothelial expression, thick arrows identify non-endothelial expression. "V" indicates vasculitis lesions. White curly brackets identify the vitreous, blue curly brackets identify the inner retina 
However, some cells infiltrating the retina and vitreous show CD31 expression, which is clearly not endothelial (Fig. 2, thick arrows), while endoglin expression seems to remain purely endothelial during EAU. This indicates a lack of specificity of CD31 expression to firmly identify retinal ECs, enhancing the necessity to combine different markers for accurate retinal EC sorting.

Healthy murine retinas were then processed into single cell suspensions by enzymatic digestion. ECs were further sorted by FACS relying on either the expression of GFP and CD31 (transgenic strategy) or the expression of CD31 and endoglin (WT strategy), both combined with the absence of CD45 expression. We have indeed detected, as previously reported in the literature, a few cells coexpressing GFP, CD31 and CD45 which may enlighten the presence of Tie2-expressing hematopoietic cells (data not shown) [27, 28]. Each sample was generated from a pool of at least 4 retinas from 2 naïve mice. As shown in Additional file 3: Fig. S3A, ECs represent about $0,1 \%$ of the retinal cell population (excluding dead cells, debris and doublets) in both strategies. The WT sorting strategy was tested on Tie2-GFP mice, as illustrated in Additional file 3: Fig. S3B. Among pre-gated CD31 + CD45- cells, the majority of cells express both endoglin and GFP. Among cells gated as endothelial with the WT strategy (endoglin+CD31 + CD45-, blue gate), the vast majority would also be selected as ECs with the transgenic sorting strategy (GFP + CD31 + CD45-, orange gate).

We also compared the purity of the EC samples sorted with the 2 sorting strategies by RNA-Seq. For transcriptome studies, retinal ECs and total live retinal cells were separately sorted, both in C57BL/6 J-Tie2-GFP mice and in C57BL/6 J WT mice. Given the low expected number of cells, each sample was sorted from a pool of 3 mice. RNA was extracted and its quality tested before being processed for RNA-Seq analysis. RNA-Seq data were first analyzed for the expression of endothelial (Tie2, Cldn5, CD31), pericyte (Pdgfrb, Abcc9, Lama2), photoreceptor (Rho, Pde6b, SAg), microglia/macrophage (Ptprc (CD45), itgam (CD11b), Cx3cr1), macroglia (Aqp4, Aldh1l1, Slc1a3) and RPE (RPE65, Rgr, Rdh10) cell markers. Figure 3a illustrates comparative expression of those retinal cell markers by ECs versus total retina (green bars represent samples obtained with the transgenic strategy; blue bars represent samples obtained with the WT strategy). EC markers are highly enriched, and all non-endothelial markers are depleted in the EC fractions, whatever the sorting strategy, with the exception of pericyte markers. We next investigated the expression of more numerous EC markers, previously identified as specifically enriched in BBB ECs [1]. As illustrated in Fig. 3b, all those barriertype EC markers are significantly enriched in the EC fractions, compared to total retina, with a similar pattern between the 2 sorting strategies.

\section{Analysis of retinal cell gene regulation during EAU}

We then induced AT EAU in C57BL/6 J WT mice and sorted live total retinal cells and retinal ECs in order to identify regulated transcripts compared to naïve mice. Each sample was sorted from a pool of at least 3 mice. We analyzed a total of 5 AT EAU samples and 4 naïve samples.

The transcriptional profiles of replicates (samples of the same nature isolated from the same pool of mice), biological duplicates (samples of the same nature isolated from different pools of mice) and samples of different nature were compared, in order to identify the source of variation. As shown in Additional file 4: Fig. S4, the dispersion is lowest for replicates, intermediate for biological duplicates and highest for samples of different nature.

A principal component analysis (PCA) was performed with all diseased and naïve retinal cell samples (Fig. 4a). PCA provides an unsupervised 2-dimensional graphic representation of the similarities and differences between samples. The PCA data show a tendency of diseased retinal cell samples (DR) to segregate from naïve retinal cell samples (NR). However, the transcriptome of 2 diseased retinal cell samples (DR4 and DR5) are closer to the cluster of naïve retinal cell samples. Those 2 samples are isolated from the only 2 pools of mice whose mean clinical grade was inferior to 2 . When those 2 samples are eliminated, clearer segregation between diseased and naïve retinal cells is brought to light (Fig. 4b). Since the aim of the project was to target the differences between EAU and naïve cells, those 2 samples were dismissed for further analysis, which was thus performed on 3 diseased samples and 4 naive samples.

Only genes with a Log fold change (FC) superior to 2 (absolute value) and a false detection rate (FDR) inferior to 0,05 were retained. With those filters, we identified 182 genes significantly regulated between diseased and naïve retinal cells, which were ranked according to their foldchange top down (Additional file 5: Fig. S5).

We then tried to classify those genes into families (Table 2).

In order to identify the different pathways in which those genes are involved, we used DAVID, Pubmed and Genecards. Four main groups were identified: 52 genes playing a role in antigen presentation to $\mathrm{T}$ cells in association with MHC class II, 45 genes implicated in cytokine and chemokine signaling pathways, 39 genes taking part in cell mobility and 18 genes that contribute to innate immunity. However, 33 genes could not be attributed to one of these categories. Genes whose function was previously described during uveitis appear in blue, genes whose function was not previously described in uveitis appear in orange. Figure 5 graphically illustrates the role of the genes classified in group 1 (antigen presentation).

RNA Seq analysis of total retinal cells mainly brought to light upregulation of genes involved in antigen presentation and $\mathrm{T}$ cell activation during EAU. This approach thus 

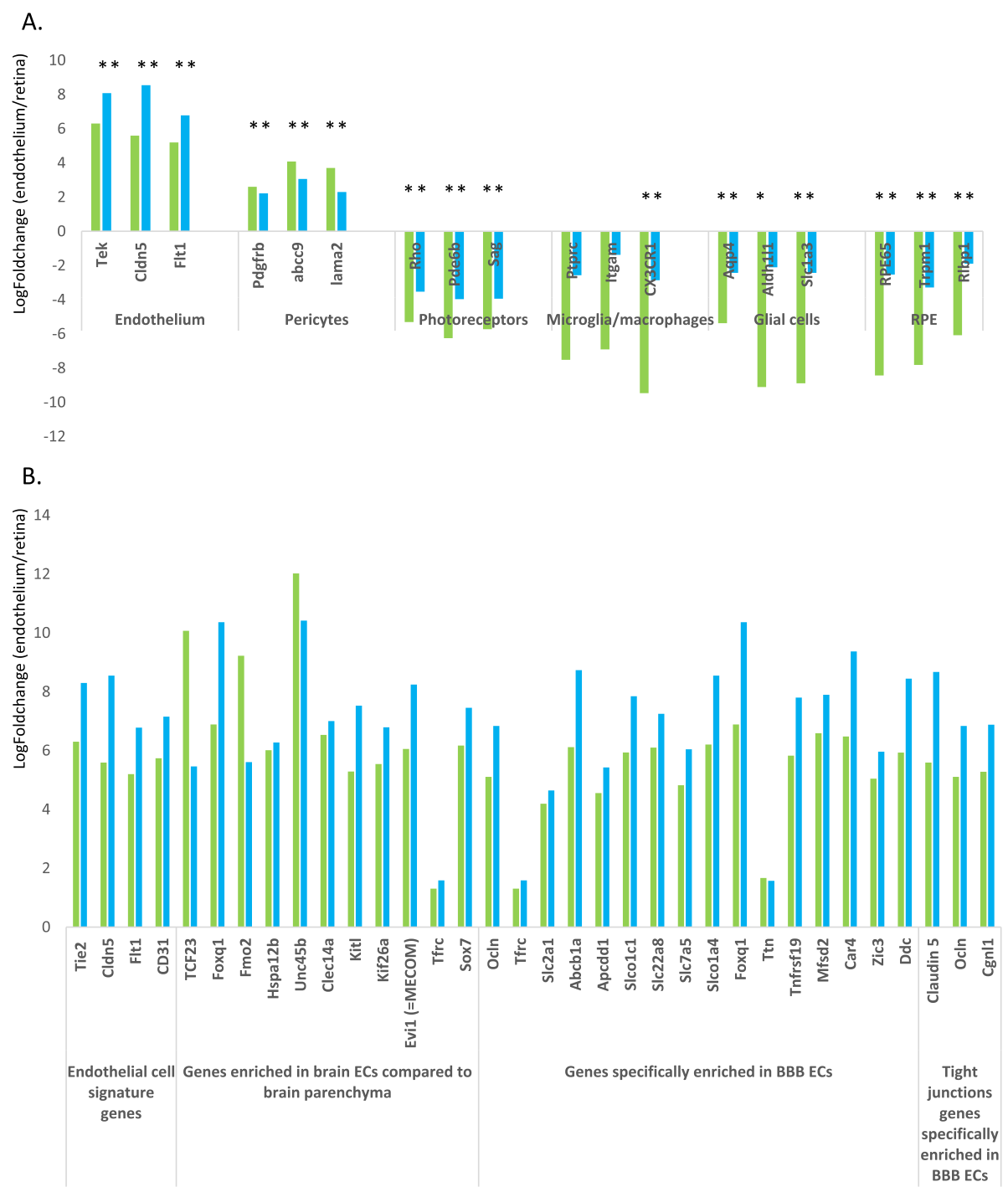

Fig. 3 Endothelial cell markers are enriched in purified endothelial cells compared to total retina. a. Purity of sorted endothelial cells. RNA-Seq data were analyzed for the expression of endothelial, pericyte, photoreceptor, microglia/macrophage, glial and RPE cell markers to evaluate the purity of the endothelial cell samples. Each bar illustrates the relative expression of one marker by endothelial cells compared to total retinal cells (LogFoldchange). Green bars represent samples sorted with the transgenic strategy, blue bars represent samples sorted with the WT strategy. * $\mathrm{FDR}<0,05,{ }^{*} \mathrm{FDR}<0,01$. b. Enrichment of barrier-type endothelial cell markers in the endothelial cell samples. RNA-Seq data were analyzed for the expression of endothelial cell (EC) markers previously identified as being specifically enriched in blood-brain barrier (BBB) ECs. Each bar illustrates the relative expression of one marker by ECs compared to total retinal cells (LogFoldchange). Green bars represent samples sorted with the transgenic strategy, blue bars represent samples sorted with the WT strategy. All represented FC reach statistical significance $(F D R<0,05)$

reflects activation of local antigen-presenting cells and invasion of the retina by immunocompetent cells but does not allow specific detection of BRB cell gene modulation. This comforted us to adopt a more specific strategy targeting ECs.

\section{Identification of retinal endothelial cell gene regulation during EAU}

Retinal ECs were isolated from the same EAU and naïve samples as total retinal cell samples, with the WT sorting strategy described above.
A principal component analysis (PCA) was performed with EAU endothelial samples (DE, diseased endothelium) and naive endothelial samples (NE, naïve endothelium) (Fig. 6). This PCA shows that DE and NE tend to cluster separately.

As illustrated in Additional file 6: Fig. S6, mRNA levels are accurately enriched or depleted for all markers used for cell sorting. As previously observed or mentioned in the literature, contamination of the transcriptome of EC samples by pericytes and photoreceptor genes was observed. Figure 7 indeed illustrates the expression of 


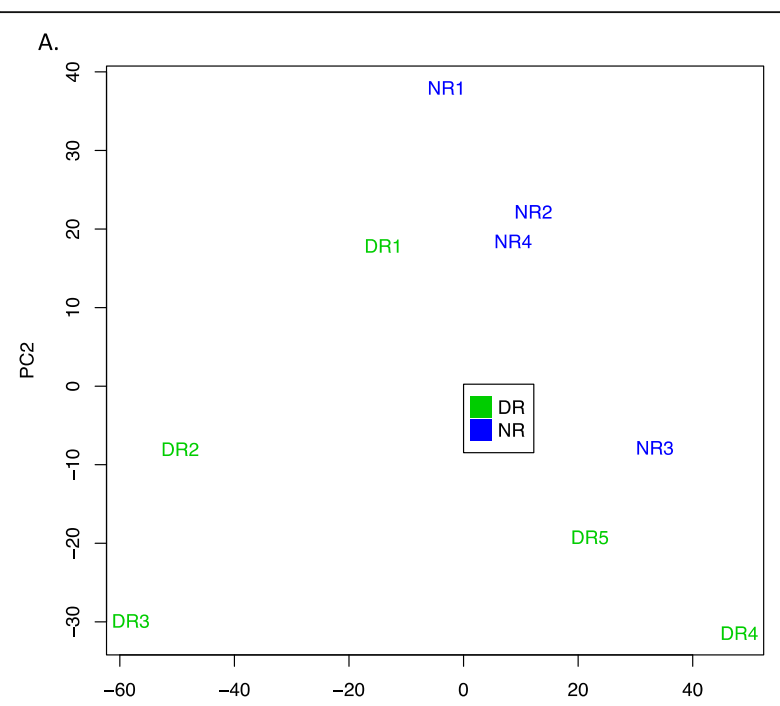

B.

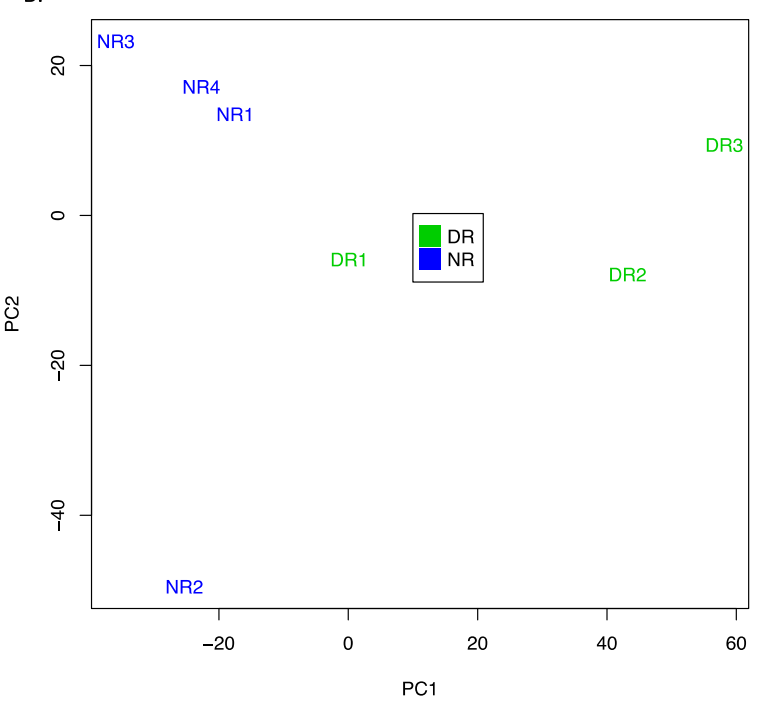

Fig. 4 Principal component analysis of EAU and naive retinal cell samples. a PCA analysis of all EAU and naïve retinal cell samples (DR: diseased retina, NR: naive retina). $\mathbf{b}$ PCA analysis after elimination of 2 DR samples

pericyte and photoreceptor cell markers by the different cell populations. The expression of pericyte markers is higher in NE samples, while expression of photoreceptor markers is predominant in DE samples.

In order to select relevant genes, we first ranked by false detection rate (FDR) the list of significantly regulated genes $(\mathrm{FDR}<0,05)$ between the 2 conditions. Unfortunately, as expected given the photoreceptor contamination, many of the highly regulated genes were photoreceptor genes, rendering the analysis tedious. In an attempt to bypass this issue, we then looked at the 120 most variant genes between DE and NE (Fig. 8). Among those 120 genes, 65 were eliminated because they did not reach statistical significance. In order to identify different profiles of gene expression, we selected a list of genes by using the bioinformatics formula 'DE significantly different from NE AND DE $\neq$ NR'. Among those, we selected 3 expression profiles in which the expression in naïve retina is low, hoping to minimize any photoreceptor gene contamination. Those 3 profiles are illustrated in Fig. 9. The first profile corresponds to genes expressed only in DE $(\mathrm{DE}+)$. The second profile corresponds to genes expressed in $\mathrm{DE}$ and in $\mathrm{DR}(\mathrm{DE}+/ \mathrm{DR}+)$. The third profile corresponds to genes expressed in $\mathrm{NE}$ only $(\mathrm{NE}+)$. Among significantly regulated genes, we identified 14 genes with the $\mathrm{DE}+$ profile, 15 genes with the $\mathrm{DE}+/ \mathrm{DR}+$ profile and 19 genes with the $\mathrm{NE}+$ profile.

Research in the literature was conducted for the most variant genes as well as for genes selected for their profile, in order to exclude genes associated with photoreceptors. 21 genes known to be expressed by photoreceptors, among which 6 genes implicated in the photo-transduction cascade, were eliminated (Additional file 7: Fig. S7). Finally, 82 candidate genes were retained, among which 10 were selected both through their variance and through their expression profile (Additional file 8: Fig. S8).

Functional analysis with the David web-based tool was performed with the list of candidate genes. A selection of gene ontology (GO) terms enriched in DE compared to NE samples is illustrated in Table 3, and includes items related to inflammation, cell adhesion, complement activation, extracellular matrix and angiogenesis.

\section{Analysis of the expression of candidate gene products}

The expression of many of the identified candidate genes was already validated in the literature, especially those with the expression profile 'DE+'. Based on the availability of antibodies, we decided to analyze the expression of 5 of the most strongly regulated candidate genes at the protein level: serpin family A member 3 (serpina3n), lipocalin 2 (lcn2), atypical chemokine receptor 1 (ackr1), laminin $\gamma 3$ (lamc3) and leucine rich alpha-2-glycoprotein 1 (lrg1). We looked at protein expression on both retinal cryosections and wholemount retinal preparations, as well as by flow cytometry when applicable.

According to RNA-Seq data, serpina3n is expressed by both DE and DR (Fig. 10). Protein expression is visualized in naïve eye cryosections at the level of the ciliary body and very discretely on some optic nerve and retinal vessels (Fig. 10b). In naïve retinal wholemounts, discontinuous serpina3n expression is observed at the vascular level (Fig. 10c). Stronger expression develops in inflamed retinas, particularly at the level of vasculitis (thick arrows), both in ECs and perivascular glial cells (Fig. 10d). However, since expression is found both at the vascular and perivascular levels, it is difficult to differentiate purely endothelial expression from perivascular expression, e.g. by infiltrating immune cells. In EAU retinal wholemounts, 
Table 2 Classification of the 182 candidate genes into 4 groups

\begin{tabular}{|c|c|c|c|c|}
\hline $\begin{array}{l}\text { Ag presentation and } \mathrm{T} \text { cell } \\
\text { activation }\end{array}$ & Cytokines/Chemokines & Cytoskeleton & Innate immunity & Others \\
\hline Ctla4 & Ccl22 & Gfap & Serpina3n & Wdfy4 \\
\hline $\mathrm{Cd} 3 \mathrm{e}$ & $\mathrm{Ccr} 7$ & Fgf2 & C3 & $\operatorname{Edn} 2$ \\
\hline $\mathrm{Cd} 3 \mathrm{~g}$ & $\mathrm{Ccr} 2$ & Antxr2 & $\operatorname{Lcn} 2$ & Hmhal \\
\hline II17a & Stat4 & Lyn & Cybb & Cend2 \\
\hline II2ra & I118r1 & Cytip & Serping1 & Arhgap30 \\
\hline H2-Eb1 & Cc15 & Lsp1 & $\mathrm{C} 4 \mathrm{~b}$ & Scube1 \\
\hline $\mathrm{H} 2-\mathrm{Aa}$ & $\mathrm{Il1b}$ & Rac2 & P2ry10 & Shisa5 \\
\hline $\mathrm{H} 2-\mathrm{Ab} 1$ & Irf8 & Dock2 & Nlrc5 & AW112010 \\
\hline Icos & Cxcr4 & Lcp1 & Gpr132 & Bazla \\
\hline Cd74 & Tgfb1 & Itgb2 & Lyz2 & Plbd1 \\
\hline $\mathrm{I} 17 \mathrm{r}$ & Stat 1 & $\mathrm{Bin} 2$ & Fg12 & Rassf2 \\
\hline $\mathrm{II} 2 \mathrm{rb}$ & $\mathrm{Csf} 2 \mathrm{rb}$ & $\mathrm{Cd} 53$ & Clec7a & Rin3 \\
\hline Ptprc & Gimap4 & Itgal & Plac8 & Scarna3b \\
\hline $\mathrm{Cd} 4$ & Gm1966 & Selplg & Irgm1 & Zbtb7c \\
\hline Mki67 & Rgs1 & S100a11 & Parp10 & Tes \\
\hline Tap1 & $\mathrm{Bcl} 3$ & S100a6 & Apobec3 & Tgif1 \\
\hline Cd52 & Tnfrsflb & Lad1 & Zc3hav1 & Prag1 \\
\hline II $2 \mathrm{rg}$ & Tgfbi & Myolf & Srgn & Gramd3 \\
\hline $\mathrm{H} 2-\mathrm{K} 1$ & Ifi203 & S100a4 & $\operatorname{Irgm} 2$ & Lrrc2 \\
\hline $\mathrm{Cd} 274$ & Igtp & Fxyd5 & Litaf & Btc \\
\hline Ptpn22 & Jak3 & Ptk2b & Ucp2 & Tmem176a \\
\hline H2-D1 & Nudt6 & Corola & $\mathrm{A} 2 \mathrm{~m}$ & Olfm3 \\
\hline Ets1 & Pik3cg & Adam19 & Gbp7 & Galnt16 \\
\hline Runx1 & Elf4 & Arhgdib & Parp12 & Kcnj5 \\
\hline Irf4 & Parp9 & $\mathrm{Cnn} 2$ & Mpeg1 & Calb1 \\
\hline H2-Q4 & Birc3 & St8sia4 & Fcerlg & 4931408D14Rik \\
\hline $\mathrm{H} 2-\mathrm{T} 23$ & Gbp2 & Myolg & Trim21 & \\
\hline Ctsh & Inpp5d & Fmnll & Oas12 & \\
\hline Socs 3 & Dtx31 & Dock10 & & \\
\hline Tар2 & Pim1 & Pcolce & & \\
\hline Gimap3 & Irf9 & Itgb7 & & \\
\hline Ms4a6b & Sp100 & Coro $2 a$ & & \\
\hline Themis & Prkcd & Itgae & & \\
\hline Sla & Fosl2 & Wipf1 & & \\
\hline Ms4a4b & Cebpd & Ahnak & & \\
\hline Ikzf3 & & Nckap11 & & \\
\hline $\operatorname{Sh} 2 \mathrm{~d} 2 \mathrm{a}$ & & Tagln2 & & \\
\hline Spn & & Adgre5 & & \\
\hline Fyb & & Pcdhb2 & & \\
\hline Cd28 & & & & \\
\hline Runx3 & & & & \\
\hline Ikzf1 & & & & \\
\hline Lcp2 & & & & \\
\hline & & & & \\
\hline Laptm5 & & & & \\
\hline Lck & & & & \\
\hline $\mathrm{B} 2 \mathrm{~m}$ & & & & \\
\hline Trim30a & & & & \\
\hline Ctss & & & & \\
\hline $\mathrm{Rfx} 2$ & & & & \\
\hline Ptpn6 & & & & \\
\hline Grap2 & & & & \\
\hline Runx2 & & & & \\
\hline Ifi30 & & & & \\
\hline
\end{tabular}

Legend: 182 genes were found to be significantly regulated between diseased and naïve retinal cells. Those genes were classified into 4 main groups. Genes whose function was previously described during uveitis appear in blue, genes whose function was not previously described in uveitis appear in orange

serpina3n expression is found on most retinal vessels, colocalized with CD31 and is particularly intense at the level of inflamed vessels (thick arrows) (Fig. 10e).

Lcn2 also has a DE+/DR+ expression profile (Fig. 11a). In naïve retinal cryosections, lcn2 expression is faintly present on the inner limiting membrane (Fig. 11b), while naïve retinal wholemounts show sparse lcn2 expression along rare retinal vessels (Fig. 11c, arrows). In EAU retinal cryosections, lcn2 staining has a macroglial aspect, particularly at the perivascular level. However, it does not seem to co-localize with CD31 (Fig. 11d). In EAU retinal wholemounts, although some co-staining with CD31 is observed (Fig. 11e, arrows), with a larger zoom lcn2 expression seems to be mostly perivascular (Fig. 11f).

Ackr1 belongs to the same DE+/DR+ profile. Ackr1 expression is purely endothelial and appears only in 


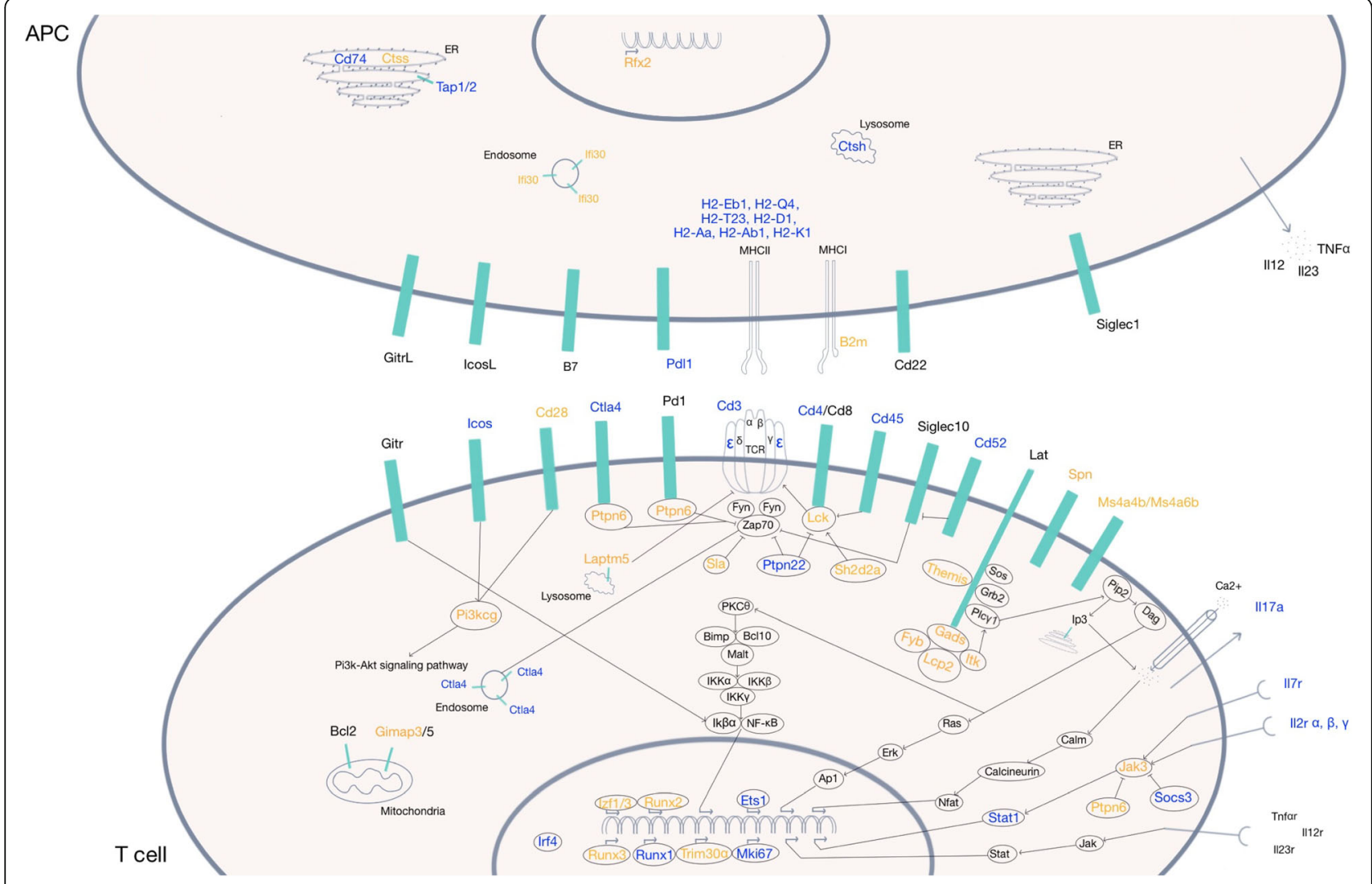

Fig. 5 Schematic representation of the interaction between an antigen-presenting cell and a T cell. In orange: genes whose expression or function was not previously described in the context of uveitis. In blue: genes whose expression or function was previously described in the context of uveitis. In black: genes that do not belong to the list of 182 candidate genes

EAU cryosections (Fig. 12c) and wholemounts (Fig. 12d). This upregulation of ackr1 expression during EAU is confirmed by flow cytometry data (Fig. 12e and f). On average, $2 \%$ of naïve retinal ECs express ackr1, while 30, $3 \%$ of retinal ECs express ackr1 during EAU. This upregulation is statistically significant $(n=3$ independent pools of 3 mice, $p$-value for unpaired t-test: 0,0003$)$.

According to RNA-Seq data, $\operatorname{lrg} 1$ is expressed only by DE (Fig. 13a). In naïve retinal sections, $\operatorname{lrg} 1$ is faintly expressed at the level of the ciliary body and at the ora serrata. No clear staining is observed in central retina (Fig. 13b). In naive retinal wholemounts, peripheral irregular expression of $\operatorname{lrg} 1$ appears at the vascular level, co-stained with CD31 (Fig. 13c). During uveitis, $\operatorname{lrg} 1$ upregulation is observed at the level of inflamed vessels on cryosections (Fig. 13d), while wholemounts show more diffuse $\operatorname{lrg} 1$ expression towards central retina than in naïve retina (Fig. 13e).

Lamc3 corresponds to the 3rd profile, with expression higher in NE than in DE (Fig. 14a). No clear difference is detected by IF on EAU versus naïve cryosections (data not shown). In retinal wholemounts, staining appears less organized and more dot-shaped in diseased retina (Fig. 14c) compared to naïve retina (Fig. 14b). However, flow cytometry data show a tendency of ECs to downregulate Lamc3 expression during EAU(Fig. 14d and e), which does not reach statistical significance (mean percentage of naïve retinal ECs expressing lamc3 45\%, mean percentage of EAU retinal ECs expressing lamc3 30,7\%, $\mathrm{n}=3$ independent pools of 3 mice, $p$-value for unpaired t-test 0,15 ).

\section{Discussion}

The BRB allows regulated transport of nutrients to the retina while preserving visual function by restricting access to toxins, pathogens and immune cells. During noninfectious uveitis and its animal model EAU, leukocytes infiltrate the retina through a disrupted BRB and induce retinal damage. As the main component of the inner $B R B$, retinal ECs are thus a central player in the development of retinal inflammation. However, the molecular basis of BRB breakdown is only partially understood.

In this study, we first investigated the activation of total retinal cells during EAU, through comparative analysis of their transcriptomic profile in EAU versus naïve retinas. The analysis of transcriptome data reveals significant regulation (mostly up-regulation) of numerous genes implicated in $\mathrm{Ag}$ presentation in association to 


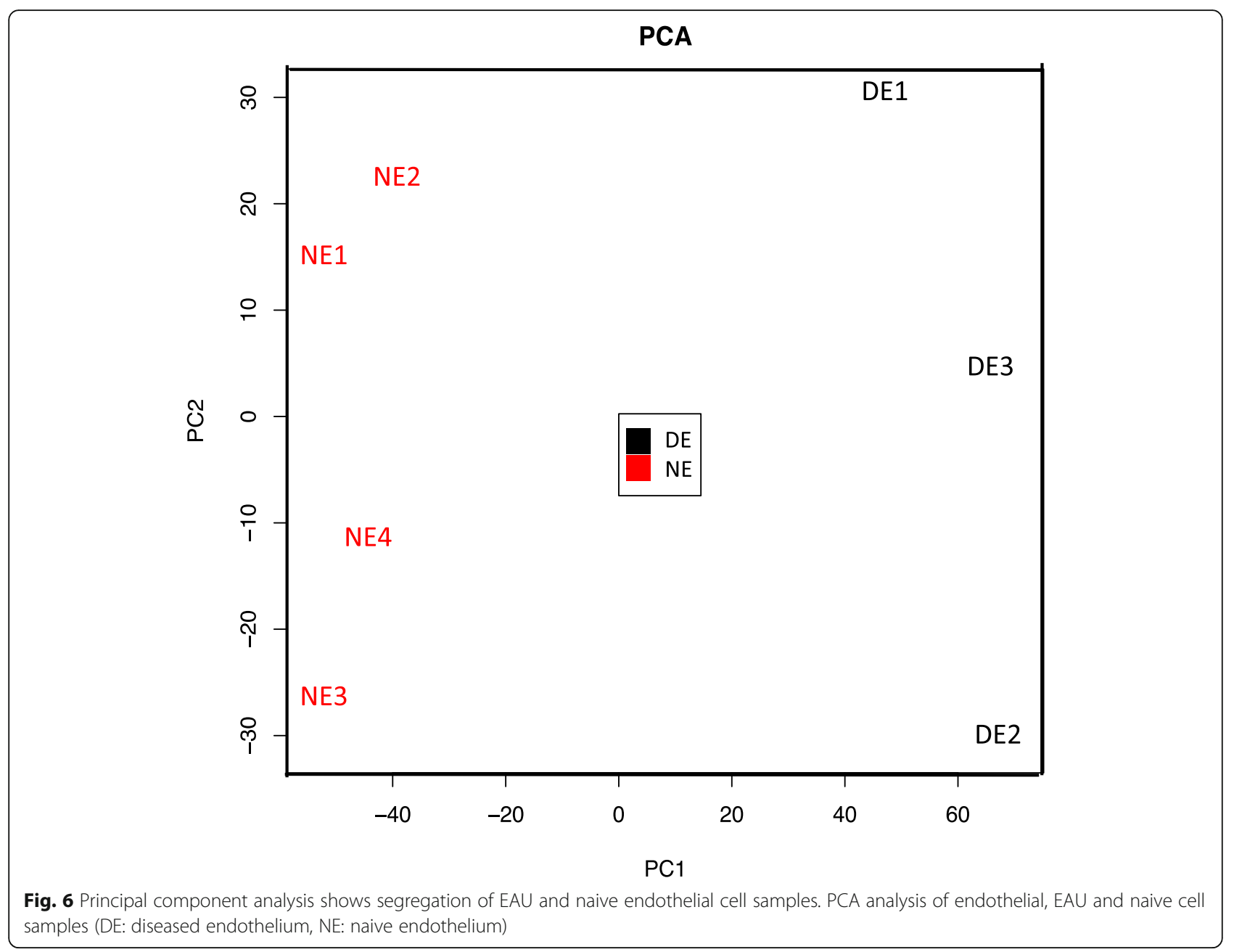

MHC Class II and T cell activation. This mainly reflects local engagement of the adaptive immune response, whose function in EAU development is already wellknown [29]. Some of those genes have already been studied as potential therapeutic targets during EAU, e.g. Icos [30], IL17R [30] or CTLA4 [31] but numerous genes have not yet been explored in the field of uveitis. For example, the tyrosine kinase Jak3 is activated by interleukin (IL) receptors IL2R and IL17R (that comprise a common chain) and plays a capital role for immune response initiation.

However, one pitfall of this approach is that cells isolated from EAU retinas comprise both resident retinal cells and infiltrating inflammatory cells. Furthermore, very few endothelial-specific genes are brought to light by this global analysis. We thus decided to investigate specifically the activation of retinal ECs during EAU, through comparative analysis of their transcriptomic profile in EAU versus naïve retinas.

Endothelial cell isolation is challenging. Many techniques such as magnetic purification (Magnetic-activated cell sorting, MACS), freeze-fracture method or scraping of the endothelium do not yield pure endothelial populations [28]. Furthermore, those last 2 methods are not applicable to retinal microvessels due to their small size. Contamination by other cell types may be eliminated by further selection, for example by culturing ECs under adapted cell culture conditions. However, although in vitro models represent a useful tool for functional analysis of candidate proteins and high-throughput testing, cultured ECs rapidly lose their barrier properties, such as the high number of tight junction proteins and low number of transcytosis vesicles [21]. These properties can be partially restored by adding astrocytes and pericytes to EC cultures [32], but no in vitro model ideally reconstitutes all properties observed in vivo, since hemodynamic conditions and effects of circulating cells and proteins are lacking.

Although Tie2-GFP transgenic mice have proved to be very useful for effective EC isolation [33], we experienced highly restrictive low transmission rates when trying to derive the Tie2-GFP transgene into a C57BL/6 J 
A.

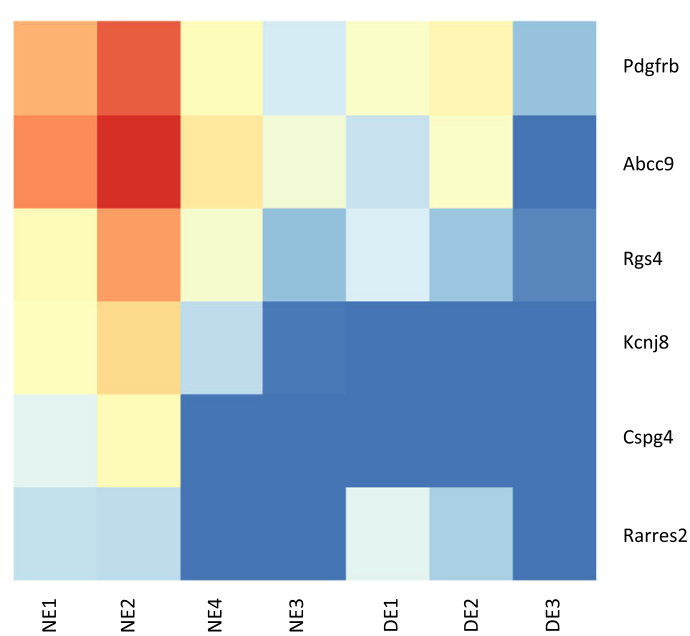

B.
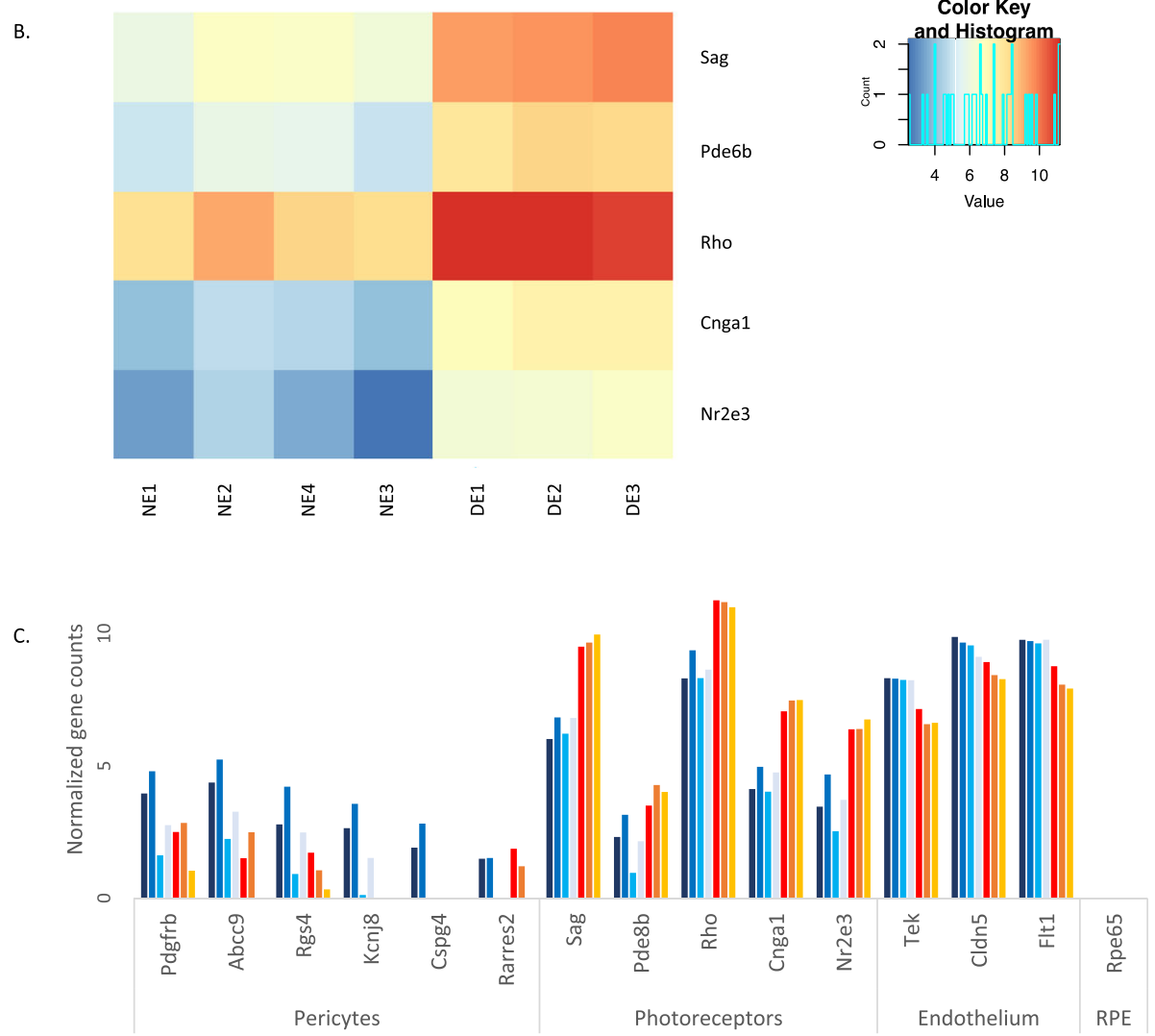
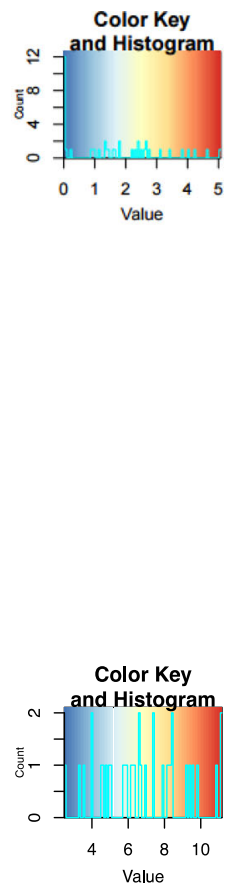

Value

Fig. 7 Identification of potential contaminants in EAU and naive retinal endothelial cell samples. a Heatmap illustrating comparative expression of pericyte markers by naive (NE) or diseased (DE) retinal endothelial cells. b Heatmap illustrating comparative expression of photoreceptor cell markers by naive (NE) or diseased (DE) retinal endothelial cells. c Histogram illustrating raw gene expression values for photoreceptor cell markers and pericyte markers by naive (NE) or diseased (DE) retinal endothelial cells. Normalized gene counts for endothelial cell markers and RPE marker RPE65 were added as reference

background, that led us to explore an alternative EC isolation strategy based only on the expression of cellsurface EC markers. Isolation of ECs often relies on CD31 expression [34]. However, our IF images provide evidence for the expression of CD31 by immune cells 


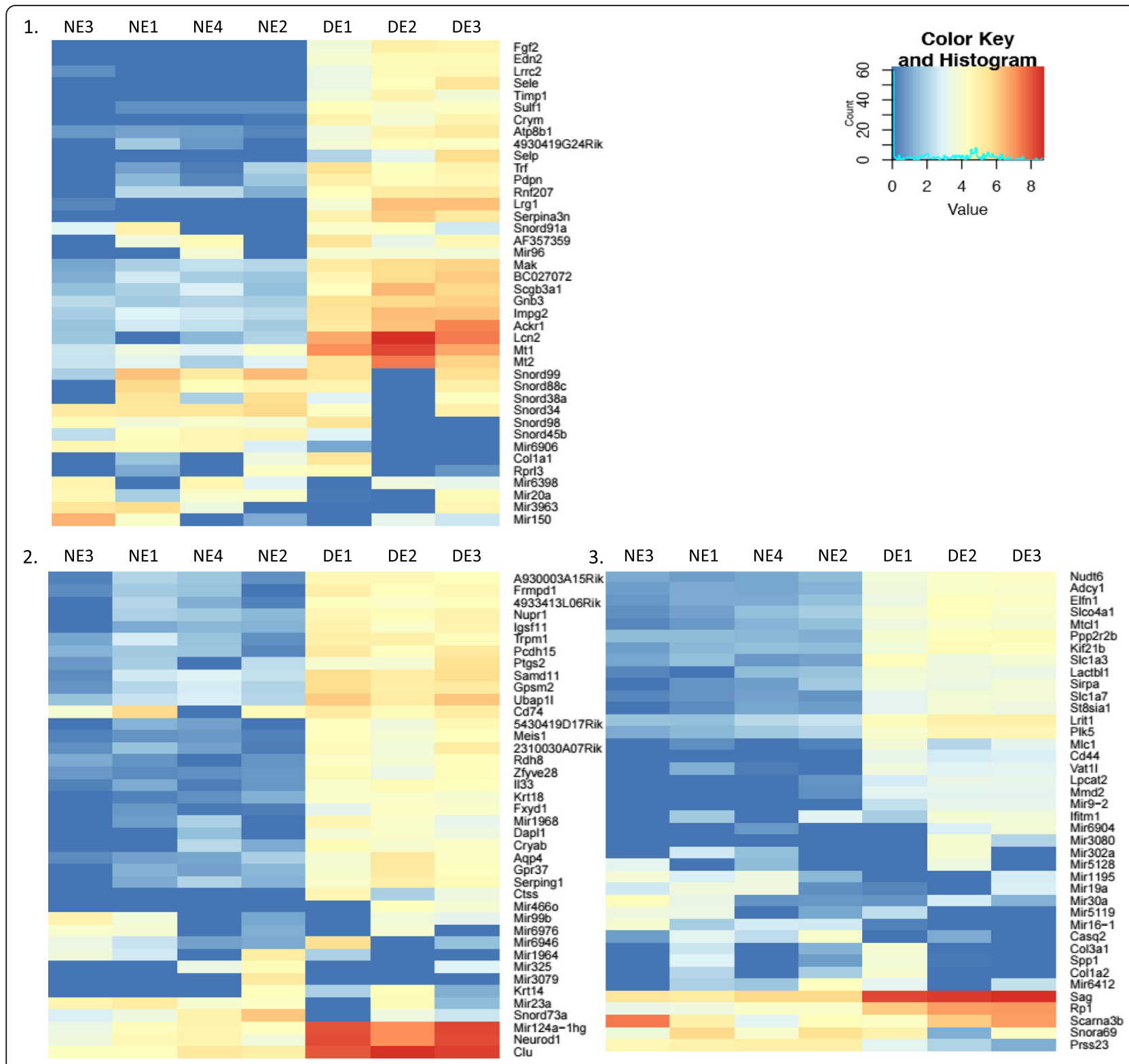

Fig. 8 Analysis of most variant genes across EAU and naive retinal endothelial cell samples. Heatmaps illustrating the expression of the 120 most variant genes between DE and NE samples

cryosections remained strictly confined to retinal vessels. We thus decided to purify ECs by flow cytometry sorting of CD31 + endoglin + double positive CD45- cells.

In our transcriptome analysis, we detected the presence of pericytes in naïve EC samples, whether sorted from Tie2GFP or WT mice. The intimate relationship between pericytes and ECs was initially described in the 1970s, pericytes being enclosed in the endothelial basement membrane and involved in adhesive junctions with ECs, rendering individualization of each cell type particularly tricky [37]. Pericytes are exceptionally abundant at the level of barriertype ECs, with a pericyte/EC ratio of 1:1 in the retina and 1: 3 in the brain, compared to 1:10 in other microvascular beds
[21]. Although the majority of the pericyte-endothelial interface is separated by a basement membrane, at some places the two cell types form focal contacts through $\mathrm{N}$-cadherin and connexins, allowing them to exchange metabolites and even ribonucleic acids [38]. Such pericyte contamination of EC samples was also observed by Daneman et al. in brain ECs sorted from Tie2-GFP transgenic mice [1]. In that study, a double FACS procedure with exclusion of cells positive for the pericyte marker PDGFRß allowed isolation of pure ECs. Unfortunately, the number of ECs that can be isolated from the retina is much lower than that obtainable from the brain, and in our experimental conditions a double FACS procedure would cause excessive cell loss. In an 


\section{A. DE $\gg$ NE - DR - NR}

\begin{tabular}{|l|l|l|l|}
\hline \multicolumn{1}{|c|}{ Gene ID } & \multicolumn{1}{|c|}{ logFC } & \multicolumn{1}{|c|}{ FDR } \\
\hline Selp & Selectine P & 7,0778737 & $2,41 \mathrm{E}-07$ \\
\hline Sele & Selectine E & 6,6168363 & $6,69 \mathrm{E}-10$ \\
\hline Lrg1 & Leucine Rich Alpha-2-Glycoprotein 1 & 6,4631616 & $1,52 \mathrm{E}-09$ \\
\hline Csf2rb2 & Colony Stimulating Factor 2 Receptor & 5,940872 & $1,44 \mathrm{E}-08$ \\
\hline Myc & V-Myc Avian Myelocytomatosis Viral Oncogene Homolog & 4,1882558 & $6,59 \mathrm{E}-05$ \\
\hline Dcn & Decorin & 4,0164888 & $1,40 \mathrm{E}-05$ \\
\hline Atp8b1 & ATPase Phospholipid Transporting 8B1 & 3,9655063 & $1,53 \mathrm{E}-10$ \\
\hline Mctp1 & Multiple C2 And Transmembrane Domain Containing 1 & 3,8066562 & $3,07 \mathrm{E}-08$ \\
\hline Chil1 & Chitinase like 1 & 3,7460334 & $2,36 \mathrm{E}-05$ \\
\hline CD14 & Myeloid Cell-Specific Leucine-Rich Glycoprotein & 3,7101772 & $1,95 \mathrm{E}-05$ \\
\hline Upp1 & Uridine Phosphorylase 1 & 3,0398881 & 0,0001072 \\
\hline Pdlim3 & Alpha-Actinin-2-Associated LIM Protein & 2,978967 & 0,0024767 \\
\hline Adamts4 & ADAM Metallopeptidase With Thrombospondin Type 1 Motif 4 & 2,5594626 & $1,14 \mathrm{E}-06$ \\
\hline Pdlim1 & Carboxyl Terminal LIM Domain Protein 1 & 2,1387075 & $\mathbf{0 , 0 0 2 7 3 2 9}$ \\
\hline & & &
\end{tabular}

Lrg1

\section{B. $D E>D R>>N E-N R$}

\begin{tabular}{|l|l|l|l|}
\hline \multicolumn{2}{|c}{ Gene ID } & logEC & FDR \\
\hline A2m & Alpha-2-Macroglobulin & $\mathbf{8 , 2 7 6 0 4 5 7}$ & $5,00 \mathrm{E}-11$ \\
\hline Serpina3n & Serpin Family A Member 3 & 8,168786 & $1,27 \mathrm{E}-11$ \\
\hline Edn2 & Endotheline 2 & 7,5692274 & $5,01 \mathrm{E}-11$ \\
\hline Prss56 & Protease serine 56 Trypsin-like & 6,7674876 & $7,55 \mathrm{E}-08$ \\
\hline Lcn2 & Lipocalin2 & 6,5088651 & $6,01 \mathrm{E}-11$ \\
\hline Ctss & Cathepsin S & 6,1614504 & $4,38 \mathrm{E}-07$ \\
\hline C4b & Complément 4b & 5,7140092 & $9,52 \mathrm{E}-11$ \\
\hline C3 & Complément 3 & 5,0588599 & $2,77 \mathrm{E}-08$ \\
\hline Timp1 & Tissue Inhibitor Of Metalloproteinases 1 & 4,8265332 & $3,31 \mathrm{E}-07$ \\
\hline Ackr1 & Atypical Chemokine Receptor 1 & 4,3302374 & $2,50 \mathrm{E}-09$ \\
\hline Lad1 & Ladinin1 & 4,2660594 & $1,35 \mathrm{E}-05$ \\
\hline Myc & V-Myc Avian Myelocytomatosis Viral Oncogene Homolog & 4,1882558 & $6,59 \mathrm{E}-05$ \\
\hline CD44 & Hematopoietic Cell E- And L-Selectin & 4,1343725 & $6,76 \mathrm{E}-11$ \\
\hline Slc14a1 & Solute Carrier Family 14 (Urea Transporter), Member 1 (Kidd Blood & 3,6650833 & $5,00 \mathrm{E}-07$ \\
\hline Itgb8 & Group) & & \\
\hline & Integrin Subunit Beta 8 & 3,6307336 & $8,86 \mathrm{E}-07$ \\
\hline
\end{tabular}
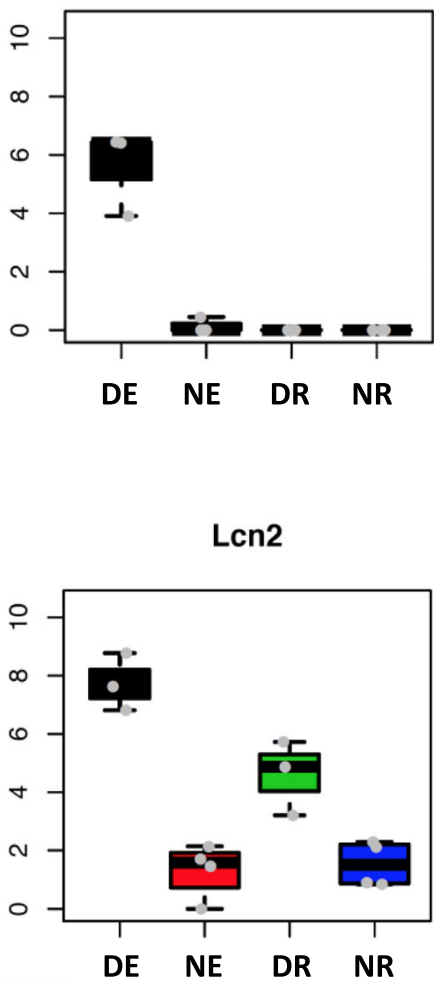

\section{NE $\gg D E-D R-N R$}

\begin{tabular}{|l|l|l|l|}
\hline & \multicolumn{1}{|c|}{ Gene ID } & \multicolumn{1}{|c|}{ logFC } & \multicolumn{1}{|c|}{ FDR } \\
\hline Mx2 & MX dynamin like GTPase 2 & $-2,067010883$ & $4,66 \mathrm{E}-05$ \\
\hline Cd83 & Cluster of Differentiation 83 & $-2,081688773$ & $6,93 \mathrm{E}-05$ \\
\hline Arhgap27os3 & Rho GTPase activating protein 27, opposite strand 3 & $-2,095551661$ & $9,99 \mathrm{E}-05$ \\
\hline 2610307P16Rik & RIKEN cDNA 2610307P16 gene & $-2,176571506$ & $7,21 \mathrm{E}-05$ \\
\hline Tcf15 & transcription factor 15 & $-2,185932389$ & 0,00179295 \\
\hline Fam181b & family with sequence similarity 181 member B & $-2,249718641$ & $1,06 \mathrm{E}-05$ \\
\hline Ism1 & isthmin 1, angiogenesis inhibitor & $-2,288692013$ & $5,08 \mathrm{E}-05$ \\
\hline Alox12 & arachidonate 12-lipoxygenase, 12S type & $-2,339247228$ & $8,25 \mathrm{E}-07$ \\
\hline Ifi213 & interferon activated gene 213 & $-2,354738894$ & 0,000161247 \\
\hline Akr1c14 & aldo-keto reductase family 1, member C14 & $-2,358814241$ & 0,000299149 \\
\hline Ifi208 & interferon activated gene 208 & $-2,390708186$ & $\mathbf{1 , 3 6 E}-05$ \\
\hline Kank4 & KN motif and ankyrin repeat domains 4 & $-2,411758073$ & $\mathbf{1 , 7 8 E}-07$ \\
\hline Trim6 & tripartite motif containing 6 & $-2,482817847$ & $5,79 \mathrm{E}-07$ \\
\hline Abcc9 & ATP-binding cassette, sub-family C member 9 & $-2,553857799$ & 0,000511325 \\
\hline Edn3 & Endothelin-3 & $-2,588324537$ & $2,31 \mathrm{E}-05$ \\
\hline Vwa3a & von Willebrand factor A domain containing 3A & $-2,619006646$ & $5,07 \mathrm{E}-06$ \\
\hline Notum & Notum & $-2,683024864$ & $3,59 \mathrm{E}-05$ \\
\hline LamC3 & Laminin, Gamma 3 & $-2,721569183$ & $8,21 \mathrm{E}-08$ \\
\hline Casq2 & Calsequestrin 2 & $-3,3713206$ & 0,00023559 \\
\hline
\end{tabular}

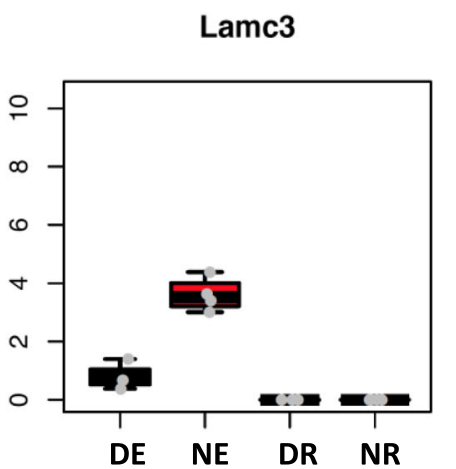

Fig. 9 Selection of candidate genes based on their expression profile. Genes were first filtered with the bioinformatics formula DE vs NE + DE $\neq$ NR. Two profiles of expression were then selected, for which the risk of contamination by photoreceptor genes is minimal. a. The first profile corresponds to genes expressed only in DE (DE+, e.g. Lrg1). $\mathbf{b}$ The second profile corresponds to genes expressed in DE and in DR (DE+/DR+, e.g. Lcn2). c The third profile corresponds to genes whose expression is down-regulated in DE versus NE (DE-, e.g. Lamc3)

attempt to exclude pericytes, we tested an anti-PDGFR $\beta$ antibody but observed only a very weak signal, hardly distinguishable from the FMO control (Additional file 9: Fig. S9). However, since it was shown that pericytes actively take part in establishing the barrier properties of the inner BRB [21], including pericytes in the analysis of gene regulation involved in BRB breakdown bears a lot of interest. Interestingly, our RNA-Seq data indicate lower pericyte contamination in EAU ECs in comparison with naïve ECs. This is consistent with the fact that BRB breakdown has been associated with pericyte dysfunction and loss. Pericyte loss in the brain was reported to be associated with upregulation of 
Table 3 Identification of functions enriched in endothelial cells during EAU

\begin{tabular}{lll}
\hline Function & Fold enrichment (DE/NE) & $P$-value \\
\hline Inflammatory response & 6,2 & $8,0 \times 10^{-4}$ \\
Innate immunity & 6,0 & $2,8 \times 10^{-2}$ \\
Cytokine activity & 5,5 & $3,4 \times 10^{-2}$ \\
Selectin superfamily & 228,8 & $8,6 \times 10^{-3}$ \\
Cell adhesion & 3,8 & $1,9 \times 10^{-2}$ \\
Leukocyte tethering or rolling & 40,9 & $4,7 \times 10^{-2}$ \\
Complement activation & 40,9 & $4,7 \times 10^{-2}$ \\
Extracellular matrix & 4,5 & $5,8 \times 10^{-2}$ \\
Positive regulation of angiogenesis & 10,1 & $6,9 \times 10^{-3}$ \\
\hline
\end{tabular}

legend: Functional analysis was performed with the Database for Annotation, Visualization and Integrated Discovery (DAVID) web-based tool on the list of identified candidate genes. The first column lists selected functions enriched in EAU endothelial samples, the second column shows fold enrichment and the third column the $p$-value

EC transcytosis and induction of several permeabilityrelated factors [39]. The role of pericytes is less clear in the retina, but pericyte loss occurs early in diabetic retinopathy [21]. Our data thus suggest that pericyte loss is also implicated in uveitis-related BRB breakdown.

We also observed contamination of EC samples by photoreceptor genes. The retina is mainly composed of rods $(80 \%)$ and many research teams have shown retinal cell transcriptome contamination by photoreceptor genes, even with extremely draconian sorting methods relying on transgenic mouse lines selectively expressing fluorescent proteins in different retinal cell types [29, 40, 41]. In this context, interestingly, McKenzie et al. studied the modification of retinal EC gene expression in different mutant models of non-neovascular remodeling by microarray, and also picked up photoreceptor gene expression in retinal vessel fractions [42]. Contrary to pericyte contamination, photoreceptor genes were more strongly expressed by diseased ECs compared to naïve. This could reflect the fact that diseased cells are more adhesive than naïve [43].

To bypass this contamination, we explored 2 approaches: the analysis of the 120 most variant genes across DE (diseased endothelium) and NE (naïve endothelium) samples and a bioinformatics analysis to select genes based on their expression profile. We then systematically eliminated remaining photoreceptor genes. By combining these 2 approaches, we identified 82 genes significantly modulated in DE compared to NE. Among those genes, a few are already known to be implicated in uveitis, such as $E$ and $P$ selectins [43], CD44 [44], IL-33 [45, 46] and Lcn2 [47]. Other genes were already implicated in other inflammatory disease models but not in uveitis, such as Lrg1 [48], Ackr1 [49] and Timp1 [50]. Finally, some of those genes are known to be involved in retinal function but not during uveitis specifically, such as Clu [51], Lrg1 [8] and Fgf2 [52].

Functional analysis of the RNA-Seq data with the DAVID web-based tool allowed to identify different pathways enriched in ECs during EAU. Among those, some enriched
GO terms were quite expected, such as those related to the inflammatory response or to cell adhesion processes. Among less expected enriched pathways in diseased retinal ECs, we found upregulation of molecules related to complement activation, extracellular matrix and angiogenesis.

A few studies have already reported involvement of the complement cascade in uveitis development [53-55], as well as in EAE pathogenesis [56].

Disruption of basement membrane and extracellular matrix components is required for immune cell migration towards inflamed sites. Proteolysis by matrix metalloproteinases (MMPs) is also involved in the regulation of EC barrier function, as well in other processes such as vascular growth and interaction with circulating immune cells [57]. Elevated levels of MMPs were found in the aqueous humor of uveitis patients, in correlation with the inflammatory activity $[58,59]$, and it was shown that specific inhibition of MMP-2 and -9 ameliorates EAU [60].

Angiogenesis is not typically associated with peak EAU. Interestingly, however, the major angiogenic factor VEGF was shown to be increased in the retina during EAU without neovascularization and involved in induction of vascular permeability, highlighting a less described implication in other processes than angiogenesis [61]. The association of sustained inflammation with angiogenesis is now well established [62] and an interplay is described in the pathogenesis of major retinal diseases. These connections between inflammation and angiogenesis are reflected by the efficacy of steroids in diabetic retinopathy [63] and of anti-VEGF in some uveitis patients [64].

Interestingly, to date, in the literature, the results of gene and protein profiling do not correlate very well [56]. Therefore, we used IF imaging on both retinal cryosections and retinal wholemounts as well as flow cytometry to validate the expression of some attractive regulated genes we identified by RNA-Seq.

Our RNA-Seq data point out an expression of serpina3n in both retinal ECs and total retina during EAU. IF images 


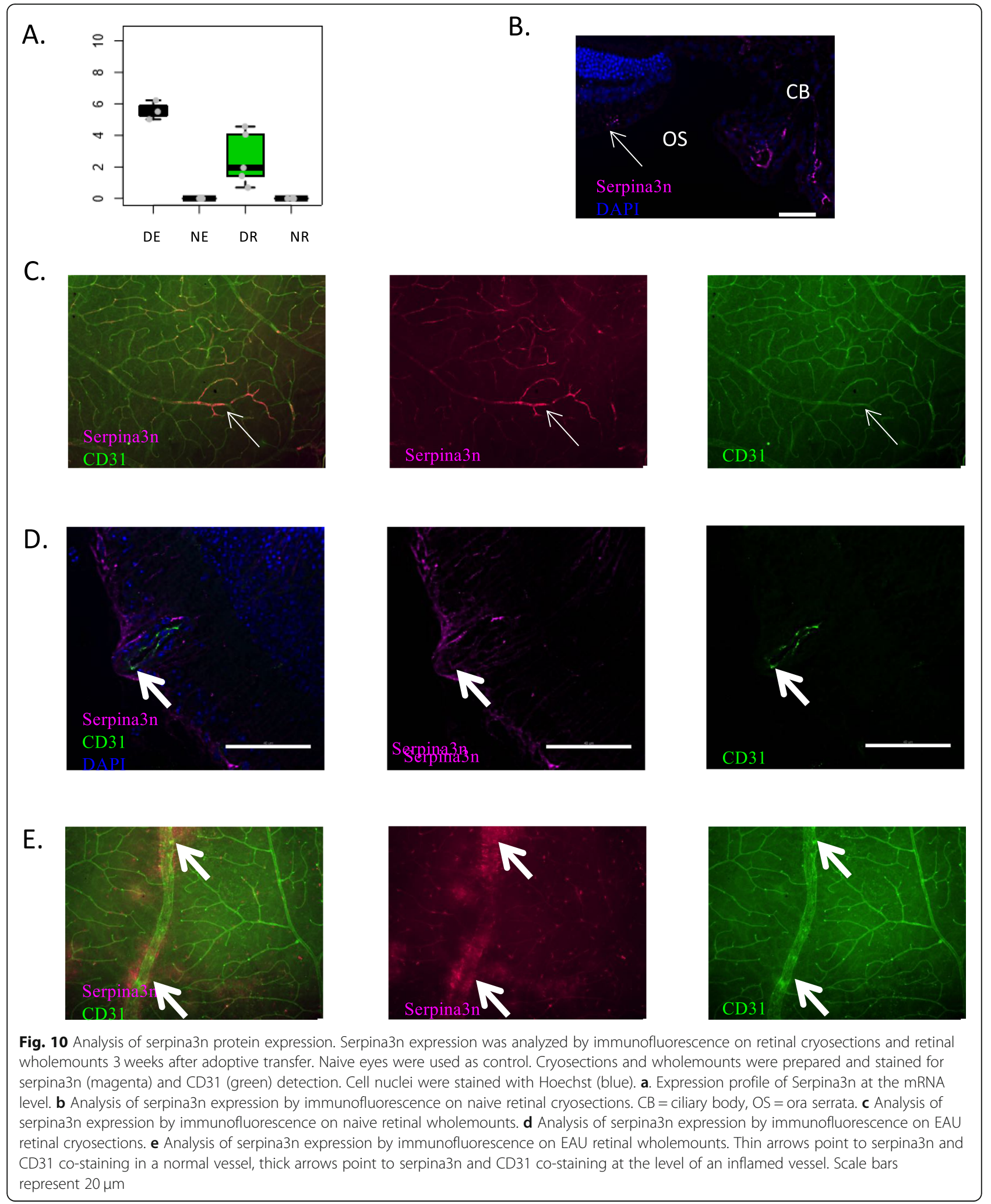

confirm that expression is strongly induced both at the vascular level and on glial cells during EAU. Serpina3n is a secreted serine protease inhibitor associated to the inflammatory response, whose expression was demonstrated in the ischemic brain and in the liver and pancreas in response to inflammatory stimuli [65]. In agreement 
A.

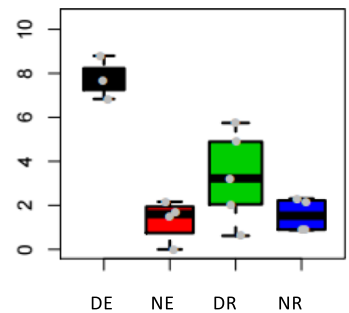

C.

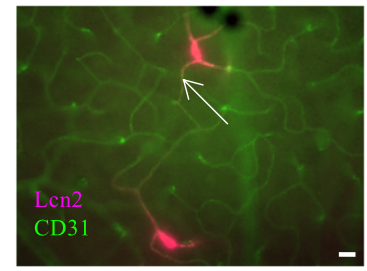

D.

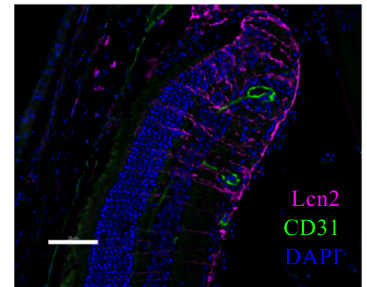

E.

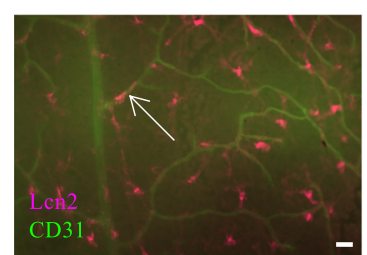

F.

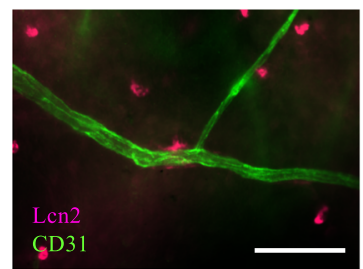

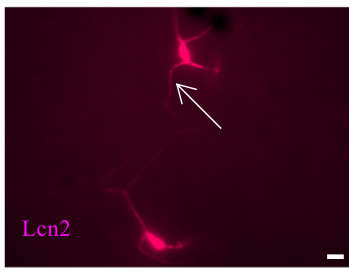
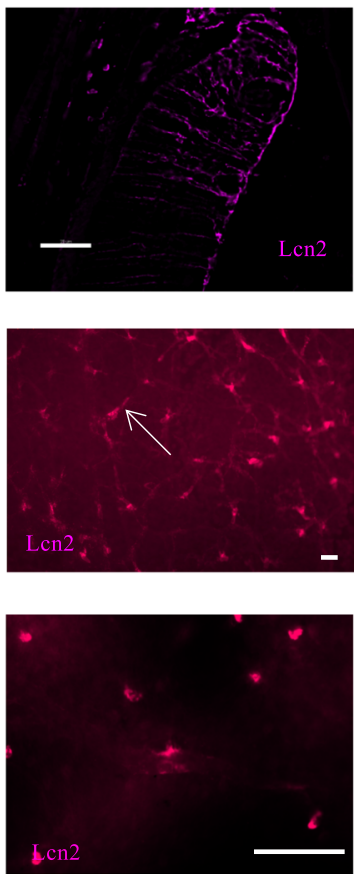

B.
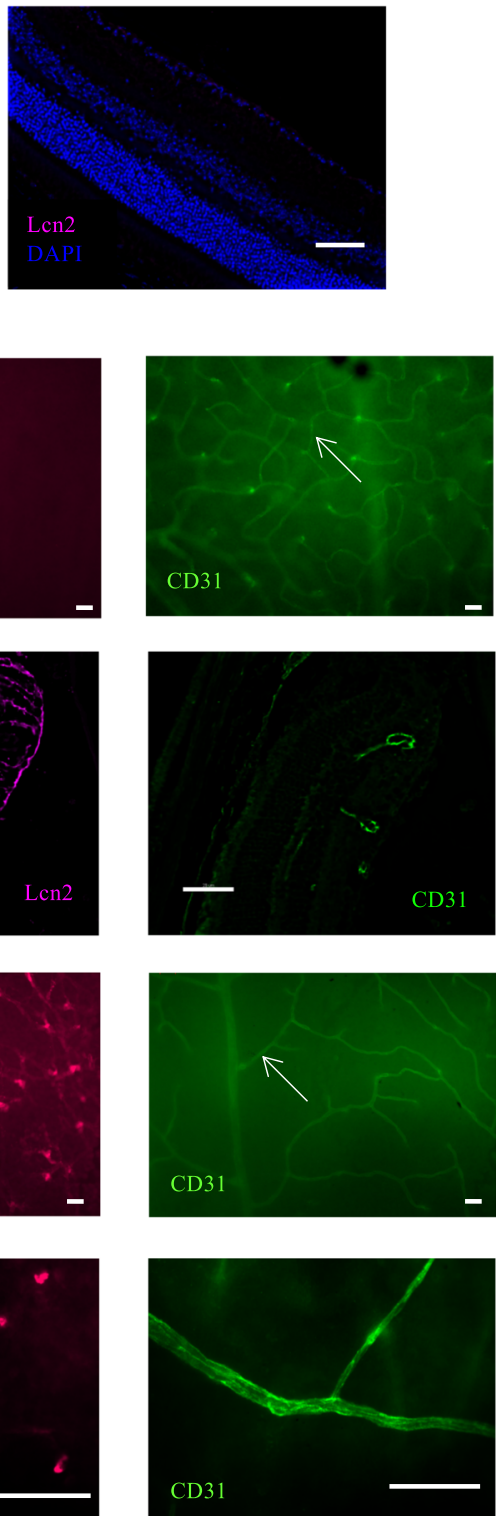

Fig. 11 Analysis of Icn2 protein expression. Len2 expression was analyzed by immunofluorescence on retinal cryosections and retinal wholemounts 3 weeks after adoptive transfer. Naive eyes were used as control. Cryosections and wholemounts were prepared and stained for Icn2 (magenta) and CD31 (green) detection. Cell nuclei were stained with Hoechst (blue). a Expression profile of Icn2 at the mRNA level. b Analysis of Icn2 expression by immunofluorescence on naive retinal cryosections. c Analysis of Icn2 expression by immunofluorescence on naive retinal wholemounts. $\mathbf{d}$ Analysis of Icn2 expression by immunofluorescence on EAU retinal cryosections. e Analysis of Icn2 expression by immunofluorescence on EAU retinal wholemounts. $\mathbf{f}$ Analysis of Icn2 expression by immunofluorescence on EAU retinal wholemounts $(\times 40$ objective). Arrows point to possible Icn2 and CD31 co-staining. Scale bars represent $20 \mu \mathrm{m}$

with our data, Takamiya et al. showed that serpina3n mRNA is induced at the perivascular level, in retinal astrocytes and uveal epithelial cells during the early phase of endotoxin-induced uveitis in rats [65]. Interestingly, serpina3n was shown to have neuroprotective effects in the EAE model, through inhibition of granzyme B [66]. Genes of the serpin family were recently found to have an altered expression in different neurological disease models, with specific involvement of serpina3n in EAE [67]. Our data suggest the potential interest of exploring serpina3n role in uveitis development.

According to our RNA-Seq data, lcn2 expression is induced in both retinal ECs and total retina during EAU. Our IF images clearly show upregulation of lcn2 expression by perivascular macroglial cells during EAU. However, although retinal wholemounts show vascular lcn2 expression, on retinal cryosections it seems that lcn2 expression is not truly attributable to ECs. Lcn2 was shown to be the most 
A.

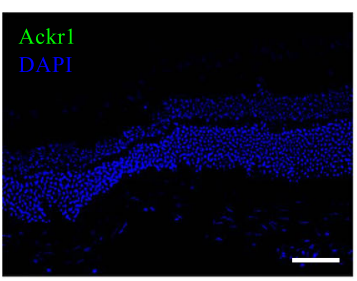

B.
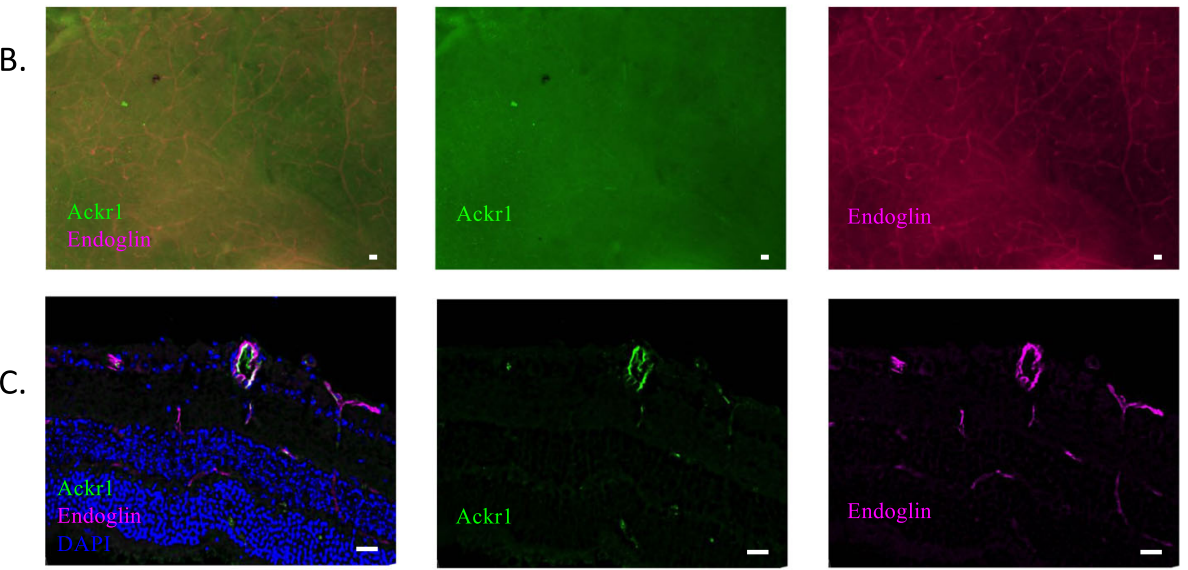

D.
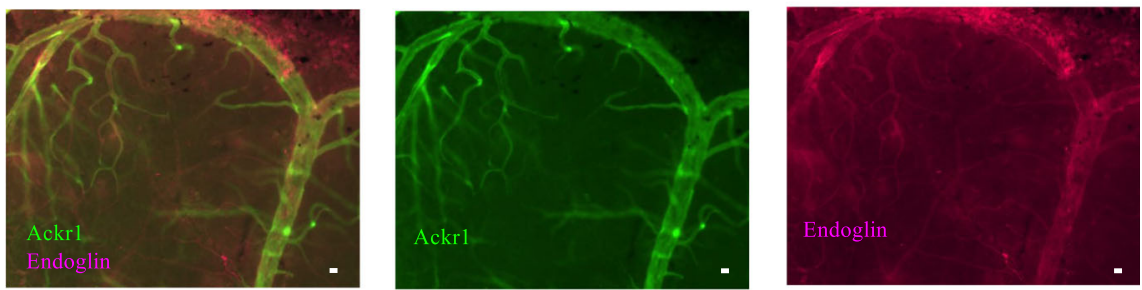

E.

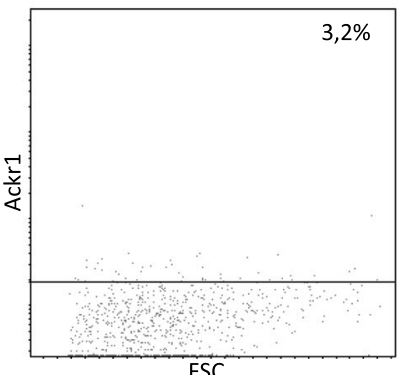

F.

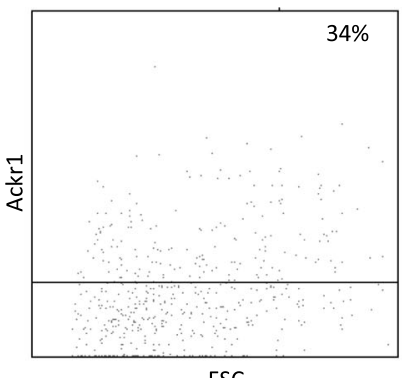

FSC

Fig. 12 Analysis of ackr1 protein expression. Ackr1 expression was analyzed by immunofluorescence on retinal cryosections and retinal wholemounts 3 weeks after adoptive transfer, as well as by flow cytometry. Naive eyes were used as control. Cryosections and wholemounts were prepared and stained for ackr1 (red or green) and CD31 (magenta) detection. Cell nuclei were stained with Hoechst (blue). a Analysis of ackr1 expression by immunofluorescence on naive retinal cryosections. b Analysis of ackr1 expression by immunofluorescence on naive retinal wholemounts. c Analysis of ackr1 expression by immunofluorescence on EAU retinal cryosections. $\mathbf{d}$ Analysis of ackr1 expression by immunofluorescence on EAU retinal wholemounts. e FACS analysis of ackr1 expression by naïve retinal endothelial (CD31+ Endoglin+ CD45-) cells. f FACS analysis of ackr1 expression by EAU retinal endothelial (CD31+ Endoglin+ CD45-) cells. Scale bars represent $20 \mu \mathrm{m}$

upregulated early stress response gene in the eye exposed to light-induced injury [68]. In agreement with our IF data, in mouse models of retinal degeneration, Müller cells were observed to respond to photoreceptor damage by expression of lcn2 [69]. Furthermore, 2 other studies in the EAE model found astrocytes and monocytes/microglia to be the major cell types expressing lcn2 [70, 71]. ECs engage in close contacts with astrocytes and Müller cells, which participate in the formation and maintenance of the BRB. These tight relationships might explain the dragging of some astrocytes and Müller cells in the EC samples during cell sorting. In the field of uveitis, lcn2 was reported to be highly induced in the equine recurrent uveitis model [72] . As concerns humans, lcn2 serum levels are increased in patients with Behçet's disease and psoriasis compared to controls [73] . Furthermore, lcn2 concentration in aqueous humor is 
A.

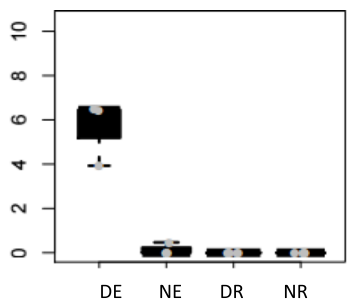

B.
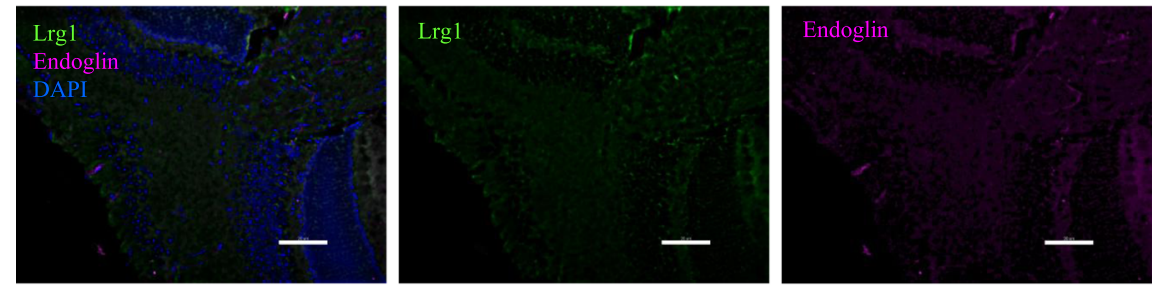

C.
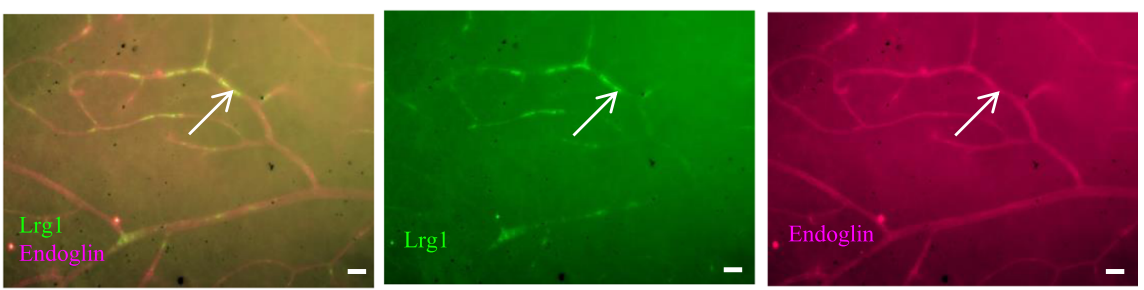

D.
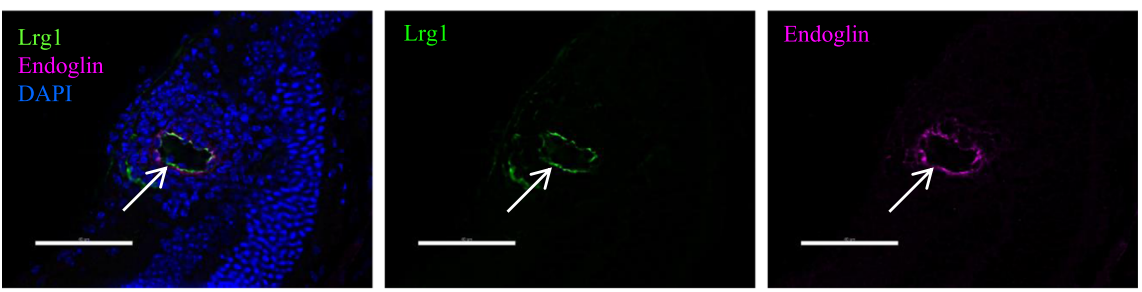

E.
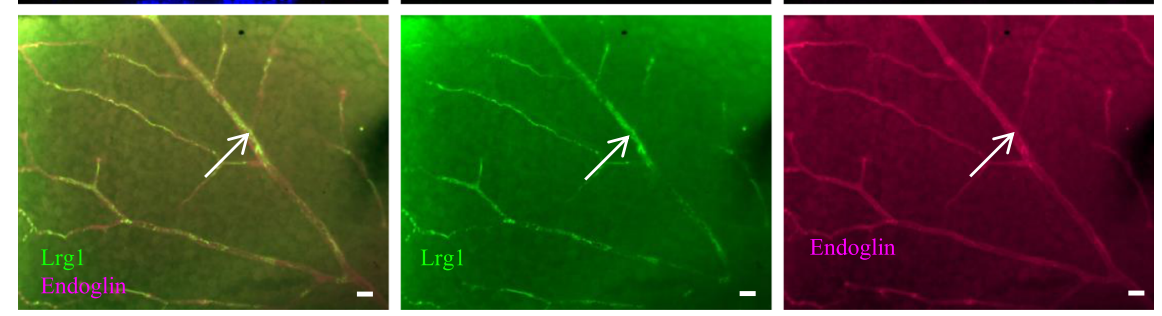

Fig. 13 Analysis of Irg1 protein expression. Lrg1 expression was analyzed by immunofluorescence on retinal cryosections and retinal wholemounts 3 weeks after adoptive transfer. Naive eyes were used as control. Cryosections and wholemounts were prepared and stained for $\operatorname{Irg} 1$ (green) and endoglin (magenta) detection. Cell nuclei were stained with Hoechst (blue). a Expression profile of Irg1 at the mRNA level. b Analysis of Irg1 expression by immunofluorescence on naive retinal cryosections. c Analysis of Irg1 expression by immunofluorescence on naive retinal wholemounts. $\mathbf{d}$ Analysis of Irg1 expression by immunofluorescence on EAU retinal cryosections. e Analysis of Irg1 expression by immunofluorescence on EAU retinal wholemounts. Arrows point to $\operatorname{lrg} 1$ and endoglin co-staining. Scale bars represent $20 \mu \mathrm{m}$

increased in eyes with idiopathic acute anterior uveitis [47]. At the functional level, Nam et al. found a pathogenic role for lcn2 in EAE development [70], while Berard et al. observed increased EAE severity in lcn2 knock-out (KO) mice [71]. Taken together, these data suggest an important yet to precise role of lcn2 in retinal response to stress.

Our RNA-Seq and IF data both point to ackr1 upregulation in diseased ECs compared to naive. Ackr1 is an atypical chemokine receptor, that binds different proinflammatory chemokines and regulates their activity by transcytosis across the endothelium, from the basolateral to the luminal side, where those chemokines contribute to leukocyte diapedesis [74]. Endothelial expression of ackr1 was shown in other experimental models of inflammatory diseases, such as atherosclerosis [75]. Upregulation of ackr1 was shown at the level of the BBB in EAE and MS.

Our RNA-Seq and IF data agree in showing that $\operatorname{lrg} 1$ is upregulated in diseased endothelium compared to naïve. Lrg1 belongs to the 'Leucine-rich Repeat' family, whose members are known to be involved in protein-protein 
A.

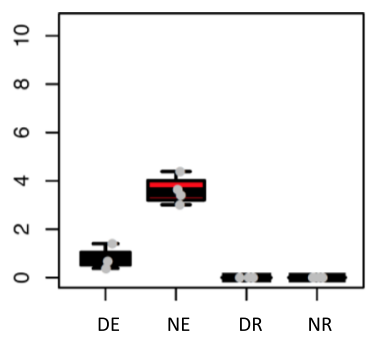

B.
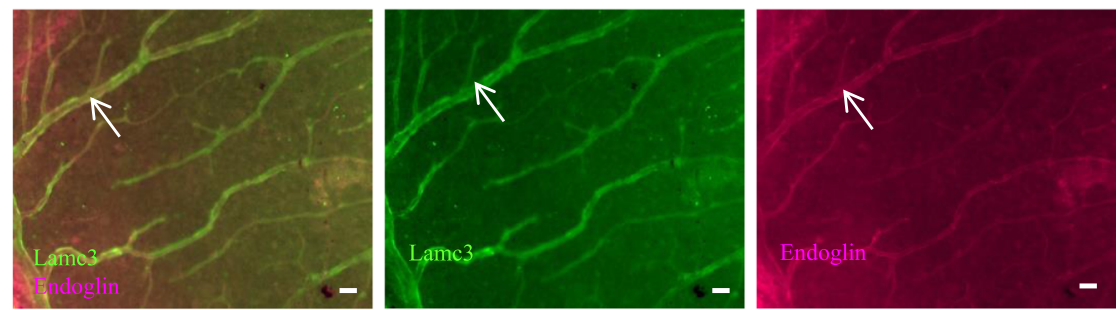

C.
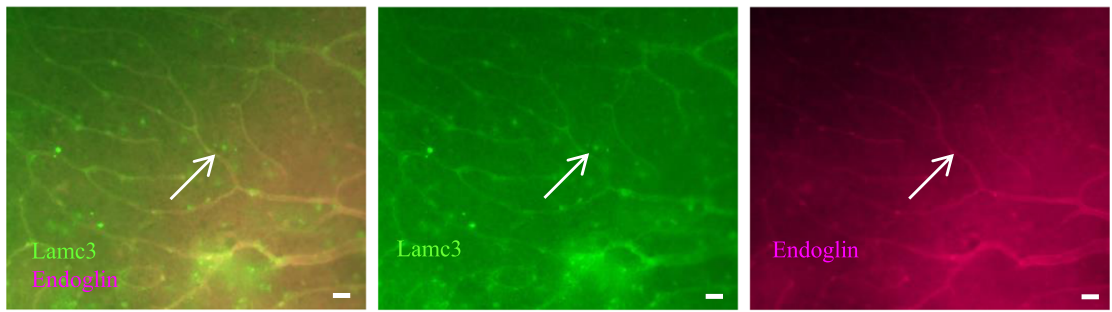

D.

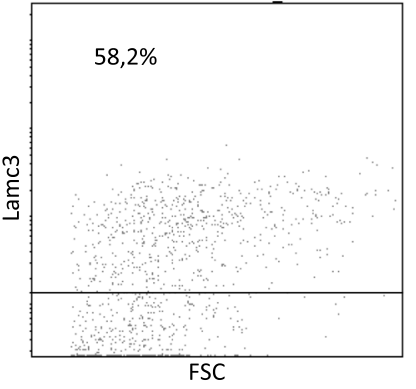

E.

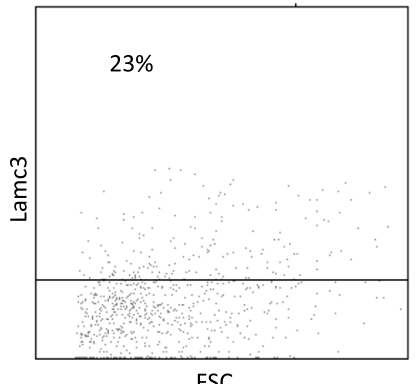

Fig. 14 Analysis of Lamc3 protein expression. Lamc3 expression was analyzed by immunofluorescence on retinal cryosections and retinal wholemounts 3 weeks after adoptive transfer. Naive eyes were used as control. Cryosections and wholemounts were prepared and stained for Lamc3 (green) and endoglin (magenta) detection. Cell nuclei were stained with Hoechst (blue). a Expression profile of Lamc3 at the mRNA level. b Analysis of Lamc3 expression by immunofluorescence on naive retinal wholemounts. c Analysis of Lamc3 expression by immunofluorescence on EAU retinal wholemounts. d FACS analysis of Lamc3 expression by naïve retinal endothelial (CD31+ Endoglin+ CD45-) cells. e FACS analysis of Lamc3 expression by EAU retinal endothelial (CD31+ Endoglin+ CD45-) cells. Arrows point to possible Lamc3 and endoglin co-staining. Scale bars represent $20 \mu \mathrm{m}$

interactions, signal transduction, cell adhesion and development [76]. Lrg1 expression in the retina was first described by Wang et al. in 2013 [8] . In this paper, $\operatorname{lrg} 1$ retinal expression is shown to be restricted almost exclusively to the vasculature and strongly upregulated in different mouse models of choroidal and retinal neovascularization, where it promotes angiogenesis [8] . Besides, $\operatorname{lrg} 1$ expression is upregulated during acute inflammation in mice, and it was proposed that it might even serve as a diagnostic inflammatory biomarker [77] . Lrg1 expression was shown to be associated with disease activity in different human diseases such as rheumatoid arthritis [78], ulcerative colitis [79] and
Crohn's disease [48] . Our data bring to light the potential role of $\operatorname{lrg} 1$ in the development of retinal inflammation.

Protein expression analysis for those 4 genes thus globally confirms vascular upregulation during EAU. However, serpina $3 \mathrm{n}$ and $\operatorname{lcn} 2$ are also detected at the perivascular level, mainly on glial cells. Such perivascular expression probably exists for other genes in our list. However, as previously mentioned for pericytes, macroglial cells being part of the inner BRB, study of gene regulation at their level is also clearly relevant in the context of our work.

Unlike the previous genes for which protein validation was performed, RNA-Seq data point to downregulation of 
lamc3 expression in DE compared to NE. Although downregulation is not clearly observed by IF, flow cytometry data show a tendency of ECs to downregulate lamc3 expression during EAU. Lamc3 is a poorly described member of the laminin family, which are a major component of the vascular basement membrane. Lamc3 was shown to play a role in vascular branching and EC proliferation during angiogenesis, though interaction with microglial cells [80].

Our RNA-Seq data confirm the absence of MHC Class II expression in ECs, even during EAU. The only candidate gene possibly involved in $\mathrm{Ag}$ presentation is $\mathrm{Ca}$ thepsin S (Ctss). However, Ctss was also reported to be implicated in EC dysfunction and in particular in microvascular complications of diabetes [81].

In our data, most genes were upregulated in DE compared to NE. Functional analysis of our list of candidate genes seems to indicate that some 'permeability' genes are upregulated in retinal ECs during BRB breakdown. Munji et al. performed vast transcriptome studies on isolated $\mathrm{BBB}$ ECs in experimental models of different $\mathrm{BBB}$ breakdown-associated diseases: stroke, MS, brain injury and epilepsy. With this approach, they identified a set of genes whose altered expression is shared between models, that was named the $B B B$ dysfunction module [67]. Interestingly, this dysfunction module contained mainly peripheral endothelial genes, suggesting that $\mathrm{BBB}$ breakdown rather implies upregulation of 'permeability' genes than downregulation of 'barrier' genes. No study has investigated yet whether this might also be the case in BRB breakdown.

\section{Conclusions}

In conclusion, our work provides the first transcriptomic study on total retinal cells and retinal ECs during EAU. Our data not only corroborate the involvement of molecules known for a pathogenic role in retinal inflammation, but further provide a list of new molecules regulated in inner BRB cells during uveitis. These molecules represent potential novel therapeutic targets for the development of biologic drugs to treat human inflammatory eye disorders.

\section{Supplementary information}

Supplementary information accompanies this paper at https://doi.org/10. 1186/s12886-020-1333-5.

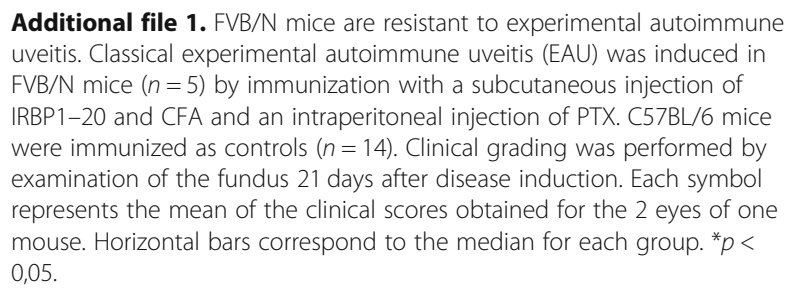
uveitis. Classical experimental autoimmune uveitis (EAU) was induced in FVB/N mice $(n=5)$ by immunization with a subcutaneous injection of IRBP1-20 and CFA and an intraperitoneal injection of PTX. C57BL/6 mice were immunized as controls $(n=14)$. Clinical grading was performed by examination of the fundus 21 days after disease induction. Each symbol represents the mean of the clinical scores obtained for the 2 eyes of one mouse. Horizontal bars correspond to the median for each group. ${ }^{*} p<$ 0,05 .

Additional file 2. Transmission rate of the Tie2-GFP allele with successive backcrossing generations into a C57BL/6 background. C57BL/6-Tie2GFP mice were generated by crossing of FVB/N Tie2-GFP males with WT C57BL/6 J female mice (to generate F1) and subsequent backcrossing of genetically selected Tie2-GFP carrier males with WT C57BL/6 J females over 10 generations. Mice were genotyped by PCR on genomic DNA extracted from tail samples.

Additional file 3. Sorting of retinal endothelial cells with the wild type strategy. a Flow cytometry sorting strategy illustrated on a WT retina: retinas of C57BL/6 WT mice were carefully dissected, cut into small pieces and dissociated by incubation with Liberase $\mathrm{DL}$ and DNase I at $37^{\circ} \mathrm{C}$ for $45 \mathrm{~min}$. The single cell suspensions, excluding dead cells (DAPI+), were analyzed by flow cytometry for CD45, CD31 and endoglin detection using fluorochrome-conjugated specific antibodies. Only CD45- cells are shown. b Flow cytometry sorting strategies illustrated on a heterozygous Tie2-GFP FVB/N-C57BL/6 retina: a first gate was placed on CD31+ CD45cells. Among those gated cells, 92\% express both GFP and endoglin. Cells that would be sorted according to the transgenic strategy are gated in orange. Cells that would be sorted according to the WT strategy are gated in blue.

Additional file 4. Comparison of transcriptional profiles between replicates, biological duplicates and different samples. Data are represented as a dot plot on a logarithmic scale. a. Correlation in gene expression between 2 samples of naive retinal cells, sorted from the same pool of mice. b. Correlation in gene expression between 2 samples of naive retinal cells, sorted from different pools of mice. c. Correlation in gene expression between 1 sample of diseased retinal endothelial cells and 1 sample of naive retinal cells. $N R=$ naïve retina, $D E=$ diseased endothelium.

Additional file 5. Integration of RNAseq data into a schematic table of the 182 genes significantly regulated between diseased and naive retinal cells.

Additional file 6. Expression of markers used for cell sorting at the mRNA level. Data are represented as boxplots of normalized mRNA expression levels (presented as Log $_{2}$ FPKM). DE $=$ diseased endothelial cells, NE $=$ naïve endothelial cells

Additional file 7. Table showing the 21 photoreceptor genes eliminated from the list of candidate genes. Photoreceptor genes were eliminated from the list of genes that were previously selected through the approach by expression profile (green), through the approach by variance (orange) or though both approaches (grey).

Additional file 8. List of the 82 candidate genes. 82 candidate genes were chosen based on the 2 selection strategies (by variance and/or by expression profile) and ranked by foldchange. Genes in grey correspond to those selected through both analyses. Genes in green were identified through the analysis by expression profile and those in orange through the analysis by variance.

Additional file 9. Flow cytometry analysis of PDGFRß expression by retinal cells. Retinas of C57BL/6 WT mice were carefully dissected, cut into small pieces and dissociated by incubation with Liberase DL and DNase I at $37^{\circ} \mathrm{C}$ for $45 \mathrm{~min}$. The single cell suspensions, excluding dead cells (DAPI+) were analyzed by flow cytometry for CD45, CD31, endoglin and PDGFRß expression using fluorochrome-conjugated specific antibodies. A fluorescence minus one (FMO) control was used for accurate gating (left).

\section{Abbreviations}

Ackr1: atypical chemokine receptor-1 (a.k.a. Duffy antigen receptor for chemokines or DARC); AT : adoptive transfer; BBB: blood-brain barrier; BRB : blood-retinal barrier; $C D$ : cluster differentiation; CD31 : PECAM-1, platelet endothelial cell adhesion molecule; CFA: Complete Freund's Adjuvant; DE: diseased endothelial cells; DR: diseased retinal cells; EAE: experimental autoimmune encephalomyelitis; EAU: experimental autoimmune uveitis; EC: endothelial cell; FACS: fluorescence-activated cell sorting; FC: foldchange; FDR: false detection rate; FMO: fluorescence minus one; FPKM: fragments per kilobase of exon per million mapped reads; GFP: green fluorescent protein; IF: immunofluorescence; IL: interleukin; IRBP: interphotoreceptor retinoidbinding protein; KO: knock-out; Lamc3: Laminin Subunit Gamma 3; Lcn2: lipocalin 2; Lrg1: leucine rich alpha-2-glycoprotein 1; MACS: magnetic- 
activated cell sorting; MMPs: matrix metalloproteinases; MS: multiple sclerosis; NE: naïve endothelial cells; NR: naïve retinal cells; PCA: principal component analysis; PDGFRß: platelet-derived growth factor receptor $B$; PFA: paraformaldehyde; PTX: pertussis toxin; RPE: retinal pigment epithelium; Serpina3n: serpin family A member 3; Tie2: Tek receptor tyrosine kinase; TIMPs: tissue inhibitors of metalloproteinases; WT: wild type

\section{Acknowledgements}

The authors would like to thank A. Thiriot and U. von Andrian (Harvard Medical School, Department of Immunology and Center for Immune Imaging) for generously providing us their anti-darc1 antibody as well as W. J. Brunken, Director of the Center for Vision, and The Research Foundation of State University of New York (Upstate Medical University), for generously providing us their anti-lamc3 antibody. The authors also thank Frederick Libert and Anne Lefort for their contribution to RNA sequencing, Christine Dubois for FACS sorting, Jean-Marie Vanderwinden and Michiel Martens for their microscopy and imaging guidance, Vincent Lambert and Julie Lecomte for their advice in retinal wholemount preparation, Viviane De Maertelaer for statistical analysis, Cédric Ballez, Isaline Schumacker and Louis Vaudoisey for their contribution to data formatting.

\section{Authors' contributions}

$\mathrm{DL}, \mathrm{VF}, \mathrm{RD}, \mathrm{CB}$ and $\mathrm{FW}$ designed the research project. $\mathrm{DL}, \mathrm{VF}, \mathrm{RD}$ and $\mathrm{CB}$ performed the research, collected and analyzed the data. MD performed RNA-Seq bioinformatics analysis. DL, CB and FW wrote the manuscript. LC participated in critical reviewing of the manuscript. All authors read and approved the manuscript.

\section{Authors' information}

Not applicable.

\section{Funding}

This work was supported for animal housing cost, purchase of reagents, consumables and chemicals (IF, flow cytometry, RNA extraction) and RNA sequencing by Fonds Erasme, Association Vésale, FER (Fonds d'encouragement à la recherche) and the Fonds pour la Recherche en Ophtalmologie (FRO, Ligue Braille). DL was further supported for a 2-year full-time research activity by Fonds Erasme.

\section{Availability of data and materials}

The data discussed in this publication have been deposited in NCBI's Gene Expression Omnibus [82] and are accessible through GEO Series accession number GSE144168 (https://www.ncbi.nlm.nih.gov/geo/query/acc.cgi?acc= GSE144168)

\section{Ethics approval and consent to participate}

Animals were housed at the animal facilities in accordance with European guidelines. Animal treatment conformed to the ARVO Statement for the Use of Animals in Ophthalmic and Vision Research. Ethics approval (protocol 515 N valid through May 2018 then protocol 669 N valid through May 2023) was obtained from the Ethics Committee (Comission d'Ethique du Bien-Être Animal, CEBEA, Université Libre de Bruxelles, approval number LA1230332).

\section{Consent for publication}

Not applicable.

\section{Competing interests}

The authors declare that they have no competing interests.

\section{Author details}

1Ophthalmology Group, IRIBHM (Institut de Recherche Interdisciplinaire en Biologie Humaine et Moléculaire), Université Libre de Bruxelles (ULB), Erasme Campus, Building C, Room C6.117, 808 Route de Lennik, 1070 Brussels, Belgium. ${ }^{2}$ Ophthalmology Department of Erasme Hospital, Université Libre de Bruxelles (ULB), 808 Route de Lennik, 1070 Brussels, Belgium. ${ }^{3}$ Ophthalmology Department of CHU Saint-Pierre, 322 Rue Haute, 1000 Brussels, Belgium. ${ }^{4}$ Ophthalmology Department of CHU Brugmann, 4 Place Van Gehuchten, 1020 Brussels, Belgium. ${ }^{5}$ Interuniversity Institute of Bioinformatics in Brussels, Université Libre de Bruxelles - Vrije Universiteit Brussel, La Plaine Campus, BC building, 6th floor, CP 263, Triomflaan, 1050 Brussels, Belgium.
Received: 6 August 2019 Accepted: 3 February 2020

Published online: 17 March 2020

\section{References}

1. Daneman R, Zhou L, Agalliu D, Cahoy JD, Kaushal A, Barres BA. The mouse blood-brain barrier transcriptome: a new resource for understanding the development and function of brain endothelial cells. PLoS One. 2010;5(10): e13741.

2. pubmeddev, RR C. Understanding autoimmune uveitis through animal models. The Friedenwald Lecture. - PubMed - NCBI [Internet]. [cited 2019 Nov 25]. Available from: https:/www.ncbi.nlm.nih.gov/pubmed/21450922.

3. Dewispelaere R, Lipski D, Foucart V, Bruyns C, Frère A, Caspers L, et al. ICAM1 and VCAM-1 are differentially expressed on blood-retinal barrier cells during experimental autoimmune uveitis. Exp Eye Res. 2015;137:94-102.

4. Makhoul M, Dewispelaere R, Relvas LJ, Elmaleh V, Caspers L, Bruyns C, et al. Characterization of retinal expression of vascular cell adhesion molecule (VCAM-1) during experimental autoimmune uveitis. Exp Eye Res. 2012;101: $27-35$.

5. Xu H, Dawson R, Crane IJ, Liversidge J. Leukocyte diapedesis in vivo induces transient loss of tight junction protein at the blood-retina barrier. Invest Ophthalmol Vis Sci. 2005;46(7):2487-94.

6. Zhao S, Li T, Li J, Lu Q, Han C, Wang N, et al. miR-23b-3p induces the cellular metabolic memory of high glucose in diabetic retinopathy through a SIRT1-dependent signalling pathway. Diabetologia. 2016;59(3):644-54.

7. Savage SR, Bretz CA, Penn JS. RNA-Seq reveals a role for NFAT-signaling in human retinal microvascular endothelial cells treated with TNFa. PLoS One. 2015;10(1):e0116941

8. Wang X, Abraham S, McKenzie JAG, Jeffs N, Swire M, Tripathi VB, et al. LRG1 promotes angiogenesis by modulating endothelial TGF- $\beta$ signalling. Nature. 2013:499(7458):306-11.

9. Kusuhara S, Fukushima Y, Fukuhara S, Jakt LM, Okada M, Shimizu Y, et al. Arhgef15 promotes retinal angiogenesis by mediating VEGF-induced Cdc42 activation and potentiating RhoJ inactivation in endothelial cells. PLoS One. 2012;7(9):e45858.

10. Steinle JJ, Zhang Q, Thompson KE, Toutounchian J, Yates CR, Soderland C, et al. Intra-ophthalmic artery chemotherapy triggers vascular toxicity through endothelial cell inflammation and leukostasis. Invest Ophthalmol Vis Sci. 2012;53(4):2439-45.

11. Takase H, Matsumoto K, Yamadera R, Kubota Y, Otsu A, Suzuki R, et al. Genome-wide identification of endothelial cell-enriched genes in the mouse embryo. Blood. 2012;120(4):914-23.

12. Browning AC, Halligan EP, Stewart EA, Swan DC, Dove R, Samaranayake GJ, et al. Comparative gene expression profiling of human umbilical vein endothelial cells and ocular vascular endothelial cells. Br J Ophthalmol. 2012;96(1):128-32.

13. Strasser GA, Kaminker JS, Tessier-Lavigne M. Microarray analysis of retinal endothelial tip cells identifies CXCR4 as a mediator of tip cell morphology and branching. Blood. 2010;115(24):5102-10.

14. Abukawa H, Tomi M, Kiyokawa J, Hori S, Kondo T, Terasaki T, et al. Modulation of retinal capillary endothelial cells by Müller glial cell-derived factors. Mol Vis. 2009;15:451-7.

15. Smith JR, Choi D, Chipps TJ, Pan Y, Zamora DO, Davies MH, et al. Unique gene expression profiles of donor-matched human retinal and choroidal vascular endothelial cells. Invest Ophthalmol Vis Sci. 2007:48(6):2676-84.

16. Ohtsuki S, Tomi M, Hata T, Nagai Y, Hori S, Mori S, et al. Dominant expression of androgen receptors and their functional regulation of organic anion transporter 3 in rat brain capillary endothelial cells; comparison of gene expression between the blood-brain and -retinal barriers. J Cell Physiol. 2005;204(3):896-900

17. Silverman MD, Babra B, Pan Y, Planck SR, Rosenbaum JT. Differential Eselectin expression by iris versus retina microvascular endothelial cells cultured from the same individuals. Microvasc Res. 2005;70(1):32-42.

18. Knight BC, Brunton CL, Modi NC, Wallace GR, Stanford MR. The effect of Toxoplasma gondii infection on expression of chemokines by rat retinal vascular endothelial cells. J Neuroimmunol. 2005;160(1):41-7.

19. Bharadwaj AS, Appukuttan B, Wilmarth PA, Pan Y, Stempel AJ, Chipps TJ, et al. Role of the Retinal Vascular Endothelial Cell in Ocular Disease. Prog Retin Eye Res. 2013;32:102-80.

20. Silverman MD, Zamora DO, Pan Y, Texeira PV, Baek S-H, Planck SR, et al. Constitutive and inflammatory mediator-regulated fractalkine expression in 
human ocular tissues and cultured cells. Invest Ophthalmol Vis Sci. 2003 44(4):1608-15.

21. Klaassen I, Van Noorden CJF, Schlingemann RO. Molecular basis of the inner blood-retinal barrier and its breakdown in diabetic macular edema and other pathological conditions. Prog Retin Eye Res. 2013;34:19-48.

22. Shao H, Liao T, Ke Y, Shi H, Kaplan HJ, Sun D. Severe chronic experimental autoimmune uveitis (EAU) of the C57BL/6 mouse induced by adoptive transfer of IRBP1-20-specific T cells. Exp Eye Res. 2006;82(2):323-31.

23. Xu H, Koch P, Chen M, Lau A, Reid DM, Forrester JV. A clinical grading system for retinal inflammation in the chronic model of experimental autoimmune uveoretinitis using digital fundus images. Exp Eye Res. 2008; 87(4):319-26.

24. Tachikawa M, Toki H, Tomi M, Hosoya K. Gene expression profiles of ATPbinding cassette transporter $\mathrm{A}$ and $\mathrm{C}$ subfamilies in mouse retinal vascular endothelial cells. Microvasc Res. 2008;75(1):68-72.

25. Liao Y, Smyth GK, Shi W. featureCounts: an efficient general purpose program for assigning sequence reads to genomic features. Bioinforma Oxf Engl. 2014;30(7):923-30.

26. Dennis G, Sherman BT, Hosack DA, Yang J, Gao W, Lane HC, et al. DAVID: Database for Annotation, Visualization, and Integrated Discovery. Genome Biol. 2003:4(5):P3.

27. Constien R, Forde A, Liliensiek B, Gröne H-J, Nawroth P, Hämmerling G, et al. Characterization of a novel EGFP reporter mouse to monitor Cre recombination as demonstrated by a Tie2 Cre mouse line. Genesis. 2001; 30(1):36-44.

28. Darrow AL, Maresh JG, Shohet RV. Mouse models and techniques for the isolation of the diabetic endothelium. ISRN Endocrinol. 2013;2013:165397.

29. Lipski DA, Dewispelaere R, Foucart V, Caspers LE, Defrance M, Bruyns C, et al. MHC class II expression and potential antigen-presenting cells in the retina during experimental autoimmune uveitis. J Neuroinflammation. 2017. 14(1):136.

30. Yang Y, Xiao X, Li F, Du L, Kijlstra A, Yang P. Increased IL-7 expression in Vogt-Koyanagi-Harada disease. Invest Ophthalmol Vis Sci. 2012;53(2):1012-7.

31. Sampson JF, Hasegawa E, Mulki L, Suryawanshi A, Jiang S, Chen W-S, et al. Galectin-8 Ameliorates Murine Autoimmune Ocular Pathology and Promotes a Regulatory T Cell Response. PLoS One. 2015;10(6):e0130772.

32. Wisniewska-Kruk J, Hoeben KA, Vogels IMC, Gaillard PJ, Van Noorden CJF, Schlingemann RO, et al. A novel co-culture model of the blood-retinal barrier based on primary retinal endothelial cells, pericytes and astrocytes. Exp Eye Res. 2012;96(1):181-90.

33. Motoike T, Loughna S, Perens E, Roman BL, Liao W, Chau TC, et al. Universal GFP reporter for the study of vascular development. Genes. 2000;28(2):75-81.

34. Su X, Sorenson CM, Sheibani N. Isolation and characterization of murine retinal endothelial cells. Mol Vis. 2003;9:171-8.

35. Marelli-Berg FM, Clement M, Mauro C, Caligiuri G. An immunologist's guide to CD31 function in T-cells. J Cell Sci. 2013;126(11):2343-52.

36. Aristorena M, Blanco FJ, de Casas-Engel ML, Ojeda-Fernandez L, GallardoVara $E$, Corbi $A$, et al. Expression of endoglin isoforms in the myeloid lineage and their role during aging and macrophage polarization. J Cell Sci. 2014;127(12):2723-35.

37. Matsusaka T. Tridimensional views of the relationship of pericytes to endothelial cells of capillaries in the human choroid and retina. J Electron Microsc. 1975;24(1):13-8.

38. Armulik A, Genové G, Betsholtz C. Pericytes: developmental, physiological, and pathological perspectives, problems, and promises. Dev Cell. 2011;21(2): 193-215.

39. Daneman R, Zhou L, Kebede AA, Barres BA. Pericytes are required for bloodbrain barrier integrity during embryogenesis. Nature. 2010;468(7323):562-6.

40. Whitmore SS, Wagner AH, DeLuca AP, Drack AV, Stone EM, Tucker BA, et al. Transcriptomic analysis across nasal, temporal, and macular regions of human neural retina and RPE/choroid by RNA-Seq. Exp Eye Res. 2014;129:93-106.

41. Siegert S, Cabuy E, Scherf BG, Kohler H, Panda S, Le Y-Z, et al. Transcriptional code and disease map for adult retinal cell types. Nat Neurosci. 2012;15(3): 487-95.

42. McKenzie JAG, Fruttiger M, Abraham S, Lange CAK, Stone J, Gandhi P, et al. Apelin Is Required for Non-Neovascular Remodeling in the Retina. Am J Pathol. 2012;180(1):399-409.

43. Xu H, Forrester JV, Liversidge J, Crane IJ. Leukocyte trafficking in experimental autoimmune uveitis: breakdown of blood-retinal barrier and upregulation of cellular adhesion molecules. Invest Ophthalmol Vis Sci. 2003;44(1):226-34.
44. Xu H, Manivannan A, Liversidge J, Sharp PF, Forrester JV, Crane IJ. Involvement of CD44 in leukocyte trafficking at the blood-retinal barrier. J Leukoc Biol. 2002;72(6):1133-41.

45. Cerçi P, Altıner S, İnal A, Köse K, Keskin G, Ölmez Ü. Investigating the role of IL-33 in the pathogenesis of Behçet's Disease. Acta Clin Belg. 2017;17:1-5.

46. Dick AD. Doyne lecture 2016: intraocular health and the many faces of inflammation. Eye Lond Engl. 2017;31(1):87-96.

47. Salom D, Sanz-Marco E, Mullor JL, Lopez-Prats MJ, Garcia-Delpech S, Udaondo P, et al. Aqueous humor neutrophil gelatinase-associated lipocalin levels in patients with idiopathic acute anterior uveitis. Mol Vis. 2010;16: $1448-52$.

48. Serada S, Fujimoto M, Ogata A, Terabe F, Hirano T, lijima H, et al. iTRAQbased proteomic identification of leucine-rich alpha-2 glycoprotein as a novel inflammatory biomarker in autoimmune diseases. Ann Rheum Dis. 2010;69(4):770-4.

49. Minten C, Alt C, Gentner M, Frei E, Deutsch U, Lyck R, et al. DARC shuttles inflammatory chemokines across the blood-brain barrier during autoimmune central nervous system inflammation. Brain J Neurol. 2014; 137(Pt 5):1454-69.

50. Petković F, Živanović J, Blaževski J, Timotijević G, Momčilović M, Stanojević

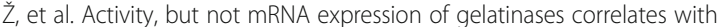
susceptibility to experimental autoimmune encephalomyelitis. Neuroscience. 2015;292:1-12

51. Zhang C, Nie J, Feng L, Luo W, Yao J, Wang F, et al. The Emerging Roles of Clusterin in Reduction of Both Blood Retina Barrier Breakdown and Neural Retina Damage in Diabetic Retinopathy. Discov Med. 2016;21(116):227-37.

52. Groeger G, Doonan F, Cotter TG, Donovan M. Reactive oxygen species regulate prosurvival ERK1/2 signaling and bFGF expression in gliosis within the retina. Invest Ophthalmol Vis Sci. 2012;53(10):6645-54.

53. Read RW, Szalai AJ, Vogt SD, McGwin G, Barnum SR. Genetic deficiency of C3 as well as CNS-targeted expression of the complement inhibitor sCrry ameliorates experimental autoimmune uveoretinitis. Exp Eye Res. 2006;82(3): 389-94.

54. Copland DA, Hussain K, Baalasubramanian S, Hughes TR, Morgan BP, Xu H et al. Systemic and local anti-C5 therapy reduces the disease severity in experimental autoimmune uveoretinitis. Clin Exp Immunol. 2010;159(3): 303-14.

55. Zhang L, Bell BA, Yu M, Chan C-C, Peachey NS, Fung J, et al. Complement anaphylatoxin receptors $\mathrm{C} 3 \mathrm{aR}$ and $\mathrm{C} 5 \mathrm{aR}$ are required in the pathogenesis of experimental autoimmune uveitis. J Leukoc Biol. 2016;99(3):447-54.

56. Alt C, Duvefelt K, Franzén B, Yang Y, Engelhardt B. Gene and protein expression profiling of the microvascular compartment in experimental autoimmune encephalomyelitis in C57B//6 and SJ mice. Brain Pathol Zurich Switz. 2005;15(1):1-16

57. Masciantonio MG, Lee CKS, Arpino V, Mehta S, Gill SE. The Balance Between Metalloproteinases and TIMPs: Critical Regulator of Microvascular Endothelial Cell Function in Health and Disease. Prog Mol Biol Transl Sci. 2017;147:10131.

58. El-Shabrawi YG, Christen WG, Foster SC. Correlation of metalloproteinase-2 and -9 with proinflammatory cytokines interleukin- 16 , interleukin-12 and the interleukin-1 receptor antagonist in patients with chronic uveitis. Curr Eye Res. 2000;20(3):211-4.

59. Di Girolamo N, Verma MJ, McCluskey PJ, Lloyd A, Wakefield D. Increased matrix metalloproteinases in the aqueous humor of patients and experimental animals with uveitis. Curr Eye Res. 1996;15(10):1060-8.

60. El-Shabrawi Y, Walch A, Hermann J, Egger G, Foster CS. Inhibition of MMPdependent chemotaxis and amelioration of experimental autoimmune uveitis with a selective metalloproteinase-2 and -9 inhibitor. J Neuroimmunol. 2004;155(1-2):13-20.

61. Vinores SA, Chan CC, Vinores MA, Matteson DM, Chen YS, Klein DA, et al. Increased vascular endothelial growth factor (VEGF) and transforming growth factor beta (TGFbeta) in experimental autoimmune uveoretinitis: upregulation of VEGF without neovascularization. J Neuroimmunol. 1998; 89(1-2):43-50

62. van Beijnum JR, Buurman WA, Griffioen AW. Convergence and amplification of toll-like receptor (TLR) and receptor for advanced glycation end products (RAGE) signaling pathways via high mobility group B1 (HMGB1). Angiogenesis. 2008;11(1):91-9.

63. Wykoff CC. Impact of intravitreal pharmacotherapies including antivascular endothelial growth factor and corticosteroid agents on diabetic retinopathy. Curr Opin Ophthalmol. 2017;28(3):213-8. 
64. Tempest-Roe S, Joshi L, Dick AD, Taylor SRJ. Local therapies for inflammatory eye disease in translation: past, present and future. BMC Ophthalmol. 2013;13(1):39.

65. Takamiya A, Takeda M, Yoshida A, Kiyama H. Expression of serine protease inhibitor 3 in ocular tissues in endotoxin-induced uveitis in rat. Invest Ophthalmol Vis Sci. 2001;42(11):2427-33.

66. Haile Y, Carmine-Simmen K, Olechowski C, Kerr B, Bleackley RC, Giuliani F. Granzyme B-inhibitor serpina3n induces neuroprotection in vitro and in vivo. J Neuroinflammation. 2015;12:157.

67. Munji RN, Soung AL, Weiner GA, Sohet F, Semple BD, Trivedi A, et al. Profiling the mouse brain endothelial transcriptome in health and disease models reveals a core blood-brain barrier dysfunction module. Nat Neurosci. 2019;22(11):1892-902.

68. Parmar T, Parmar VM, Arai E, Sahu B, Perusek L, Maeda A. Acute Stress Responses Are Early Molecular Events of Retinal Degeneration in Abca4-/Rdh8-/- Mice After Light Exposure. Invest Ophthalmol Vis Sci. 2016;57(7): 3257-67.

69. Rattner A, Nathans J. The Genomic Response to Retinal Disease and Injury: Evidence for Endothelin Signaling from Photoreceptors to Glia. J Neurosci. 2005;25(18):4540-9.

70. Nam Y, Kim J-H, Seo M, Kim J-H, Jin M, Jeon S, et al. Lipocalin-2 protein deficiency ameliorates experimental autoimmune encephalomyelitis: the pathogenic role of lipocalin-2 in the central nervous system and peripheral lymphoid tissues. J Biol Chem. 2014;289(24):16773-89.

71. Berard JL, Zarruk JG, Arbour N, Prat A, Yong WW, Jacques FH, et al. Lipocalin 2 is a novel immune mediator of experimental autoimmune encephalomyelitis pathogenesis and is modulated in multiple sclerosis. Glia. 2012;60(7):1145-59.

72. Hofmaier F, Hauck SM, Amann B, Degroote RL, Deeg CA. Changes in Matrix Metalloproteinase Network in a Spontaneous Autoimmune Uveitis Model. Invest Ophthalmol Vis Sci. 2011;52(5):2314-20.

73. Gul FC, Cicek D, Kaman D, Demir B, Nazik H. Changes of serum lipocalin-2 and retinol binding protein-4 levels in patients with psoriasis and Behçet's disease. Eur J Dermatol. 2015;25(2):195-7.

74. Salvi V, Sozio F, Sozzani S, Del Prete A. Role of Atypical Chemokine Receptors in Microglial Activation and Polarization. Front Aging Neurosci. 2017:9:148.

75. Thiriot A, Perdomo C, Cheng G, Novitzky-Basso I, McArdle S, Kishimoto JK, et al. Differential DARC/ACKR1 expression distinguishes venular from nonvenular endothelial cells in murine tissues. BMC Biol. 2017;15(1).

76. Miyajima M, Nakajima M, Motoi Y, Moriya M, Sugano H, Ogino I, et al. Leucine-Rich a2-Glycoprotein Is a Novel Biomarker of Neurodegenerative Disease in Human Cerebrospinal Fluid and Causes Neurodegeneration in Mouse Cerebral Cortex. PLoS One. 2013;8(9):e74453.

77. Shirai R, Hirano F, Ohkura N, Ikeda K, Inoue S. Up-regulation of the expression of leucine-rich alpha(2)-glycoprotein in hepatocytes by the mediators of acute-phase response. Biochem Biophys Res Commun. 2009; 382(4):776-9.

78. Fujimoto M, Serada S, Suzuki K, Nishikawa A, Ogata A, Nanki T, et al. Leucine-rich a2 -glycoprotein as a potential biomarker for joint inflammation during anti-interleukin-6 biologic therapy in rheumatoid arthritis. Arthritis Rheumatol Hoboken NJ. 2015;67(8):2056-60.

79. Serada S, Fujimoto M, Terabe F, lijima H, Shinzaki S, Matsuzaki S, et al. Serum leucine-rich alpha-2 glycoprotein is a disease activity biomarker in ulcerative colitis. Inflamm Bowel Dis. 2012;18(11):2169-79.

80. Knockdown of Laminin gamma-3 (Lamc3) impairs motoneuron guidance in the zebrafish embryo. - PubMed - NCBI [Internet]. [cited 2019 Mar 30]. Available from: https://www.ncbi.nlm.nih.gov/pubmed/?term=Knockdown+ of+Laminin+gamma-3+(Lamc3)+impairs+motoneuron+guidance+in+the+ zebrafish+embryo

81. Kumar Vr S, Darisipudi MN, Steiger S, Devarapu SK, Tato M, Kukarni OP, et al. Cathepsin S Cleavage of Protease-Activated Receptor-2 on Endothelial Cells Promotes Microvascular Diabetes Complications. J Am Soc Nephrol JASN. 2016;27(6):1635-49.

82. Edgar R, Domrachev M, Lash AE. Gene Expression Omnibus: NCBI gene expression and hybridization array data repository. Nucleic Acids Res. 2002; 30(1):207-10.

\section{Publisher's Note}

Springer Nature remains neutral with regard to jurisdictional claims in published maps and institutional affiliations.

\section{Ready to submit your research? Choose BMC and benefit from}

- fast, convenient online submission

- thorough peer review by experienced researchers in your field

- rapid publication on acceptance

- support for research data, including large and complex data types

- gold Open Access which fosters wider collaboration and increased citations

- maximum visibility for your research: over $100 \mathrm{M}$ website views per year

At $\mathrm{BMC}$, research is always in progress.

Learn more biomedcentral.com/submissions 